\title{
MICROSTRUCTURE AND TEXTURE EVOLUTION DURING GROWTH \\ OF MAGNESIO-ALUMINATE SPINEL AT CORUNDUM-PERICLASE INTERFACES UNDER UNIAXIAL LOAD: THE EFFECT OF STRESS CONGENTRATION ON REACTION PROGRESS
}

\author{
PETR JEŘÁBEK****,†, RAINER ABART*, ERIK RYBACKI***, \\ and GERLINDE HABLER*
}

\begin{abstract}
Reaction rims of magnesio-aluminate spinel were grown at the contacts between periclase and corundum at temperatures of $1250{ }^{\circ} \mathrm{C}$ to $1350{ }^{\circ} \mathrm{C}$ and under uniaxial load of 0.026 and $0.26 \mathrm{kN}$ per $9 \mathrm{~mm}^{2}$ of initial contact area. Single crystals of periclase with [100] and of corundum with [0001] perpendicular to the polished reaction interface as well as polycrystalline corundum were used as starting materials. Immediate application of the load before heating resulted in deformation twinning and fracturing of corundum introducing stress concentration and lateral variations in the quality of physical contact at the reaction interface. The tight contacts are characterized by enhanced reaction progress which together with the positive volume change of the reaction and limits on plasticity of the studied phases led to the opening of void spaces along the reaction interface and large lateral variations in rim thickness occur. Spinel shows strong topotactic relations to the reactant phases including full topotaxy between spinel and periclase, partial topotaxy with $(111)_{\text {spi }} \|(0001)_{\text {cor }}$ and $\{101\}_{\text {spi }} \mid\{10-10\}_{\text {cor }}$, and axiotaxy with (111) $)_{\text {spi }} \|(0001)_{\text {cor }}$ between spinel and corundum. Oriented nucleation and selective growth were the main mechanism of texture formation. Stress concentrations and tight physical contacts across the reaction interface may enhance nucleation of topotactic grains. The respective spinel-periclase and spinel-corundum reaction interfaces are mostly semi-coherent with sets of line dislocations accounting for the lattice misfit. The systematic occurrence of porosity along the semi-coherent and its absence along the incoherent sections of the spinel-periclase interface reflect the different capacities of the (semi)-coherent and incoherent interface sections for annihilating the vacancies that were emitted from the advancing spinel-periclase reaction interface.
\end{abstract}

Key words: Corundum (sapphire) deformation twinning, Electron Back-Scattered Diffraction, spinel-forming reaction rim, spinel topotaxy, uniaxial stress experiments

\section{INTRODUCTION}

Reaction rim growth, a particular case of diffusive phase transformation, where two phases with different compositions react to form a third phase with yet another composition at their contact, has been studied over decades (Schmalzried, 1962; Dybkov, 2009). The notion that corona microstructures, the corresponding phenomenon in rocks (Vernon, 2004), bear rate information (Joesten and Fisher, 1988; Joesten, 1991) has motivated a series of experimental calibrations of chemical mass transfer through reaction rims in geologically relevant model systems (Fisler and others, 1997; Yund, 1997; Milke and others, 2001, 2009; Gardés and others, 2011; Joachim and others, 2011, 2012). Generally, parabolic growth has been found suggesting that diffusion across the rim is rate limiting (Schmalzried, 1981). Formation of magnesio-aluminate spinel $\left(\mathrm{MgAl}_{2} \mathrm{O}_{4}\right)$ from periclase $(\mathrm{MgO})$ and corundum $\left(\mathrm{Al}_{2} \mathrm{O}_{3}\right)$ is a prototype solid-state reaction for which phase relations are well constrained (Sack,

\footnotetext{
* Department of Lithospheric Research, University of Vienna, Althanstraße 14, A-1090 Vienna, Austria ** Institute of Petrology and Structural Geology, Faculty of Science, Charles University in Prague, Albertov 6, CZ-12843 Prague, Czech Republic

*** GFZ German Research Centre for Geosciences, Helmholtz Centre Potsdam, D-14473 Potsdam, Germany

${ }^{+}$Corresponding author: jerabek1@natur.cuni.cz, +420221951534
} 
1982; Sack and Ghiorso, 1991; Hallstedt, 1992; Jung and others, 2004). Spinel growth at periclase-corundum contacts occurs by substitutional inter-diffusion of $\mathrm{Mg}^{2+}$ and $\mathrm{Al}^{3+}$ ions within a more or less fixed oxygen sub-lattice (Carter, 1961; Rossi and Fulrath, 1963). The corresponding diffusion coefficients have been determined by Whitney and Stubican (1971). In the thermodynamic analysis of spinel growth the contact conditions were taken as in local equilibrium at both reaction interfaces (Schmalzried, 1962; Pfeiffer and Schmalzried, 1989; Watson and Price, 2002), implying that the reaction interfaces are perfectly mobile. At the periclase-spinel interface the fcc oxygen sub-lattice of spinel is inherited from the fcc oxygen sub-lattice of periclase, and topotaxy with $(100)_{\text {spi }} \|(100)_{\text {per }}$ and $(010)_{\text {spi }} \|(010)_{\text {per }}$, that is a simple cube to cube correspondence, is characteristic. The interface is sharp, with short coherent segments separated by distinct misfit dislocations, which accommodate the negative lattice mismatch of -4.1 percent (Sieber and others, 1996). The situation is more complicated at the corundum-spinel interface, where the fcc oxygen sub-lattice of spinel is formed from the hcp oxygen sub-lattice of corundum. For diffusionreaction assemblies with $[0001]_{\text {cor }}$ perpendicular to the reaction interface, a topotaxy with $(111)_{\text {spi }} \|(0001)_{\text {cor }}$ and $\{101\}_{\text {spi }} \|\{10-10\}_{\text {cor }}$ correspondence at the spinel-corundum interface was found (Rossi and Fulrath, 1963; Carter and Schmalzried, 1985; Keller and others, 2010). Different topotactic relations are found, when the lattice of corundum has other orientations with respect to the reaction interface (Hesse and others, 1995).

More recently Götze and others (2010) and Keller and others (2010) investigated the effects of non-hydrostatic stress on the formation of spinel at periclase-corundum contacts. In both these studies rim growth experiments were done under uniaxial load. Keller and others (2010) observed a substantial enhancement of reaction rim growth when the normal stress on the reaction interface was changed from 3 to $30 \mathrm{MPa}$. As demonstrated by Götze and others (2010) the contribution of the imposed stress to the thermodynamic driving force for the reaction is marginal $\left(10^{-6}\right.$ of the total thermodynamic driving force). Keller and others (2010) found that the imposed stress has a major influence on texture of the spinel rim. At low load, the texture of the spinel rim was dominated by grain boundaries between twins characterized by $\Sigma$ 3 coincidence site lattice grain boundaries, whereas at high load high-angle grain boundaries between grains with general orientation prevailed. It was inferred that the different transport properties of special (twin) and general (high-angle) grain boundaries were responsible for the enhancement of rim growth under high load. In the experiments of Keller and others (2010), the load was applied before heating and the annealing time was fixed to $157 \mathrm{hrs}$, so that the evolution of microstructure and texture with time could not be documented and the mechanisms underlying microstructure and texture formation were not identified.

In this study, we present new data from spinel rim-growth experiments under uniaxial load, where two different loading procedures, immediate loading at room temperature and subsequent heating, and loading after the maximum temperature had been reached, were applied. We performed dedicated time series for both loading procedures to unravel the evolution of the internal microstructure and texture of the spinel rim. Our analysis also includes the deformation of the reactant phases and its influence on the physical contact at the reaction interface, on reaction progress and on lateral variations in rim thickness. We clearly identify the main mechanisms underlying texture formation.

METHODS

\section{Experimental and Sample Preparation}

Rim growth experiments were performed using a uniaxial creep (dead load) apparatus at GFZ Potsdam following a procedure described in detail by Götze and 


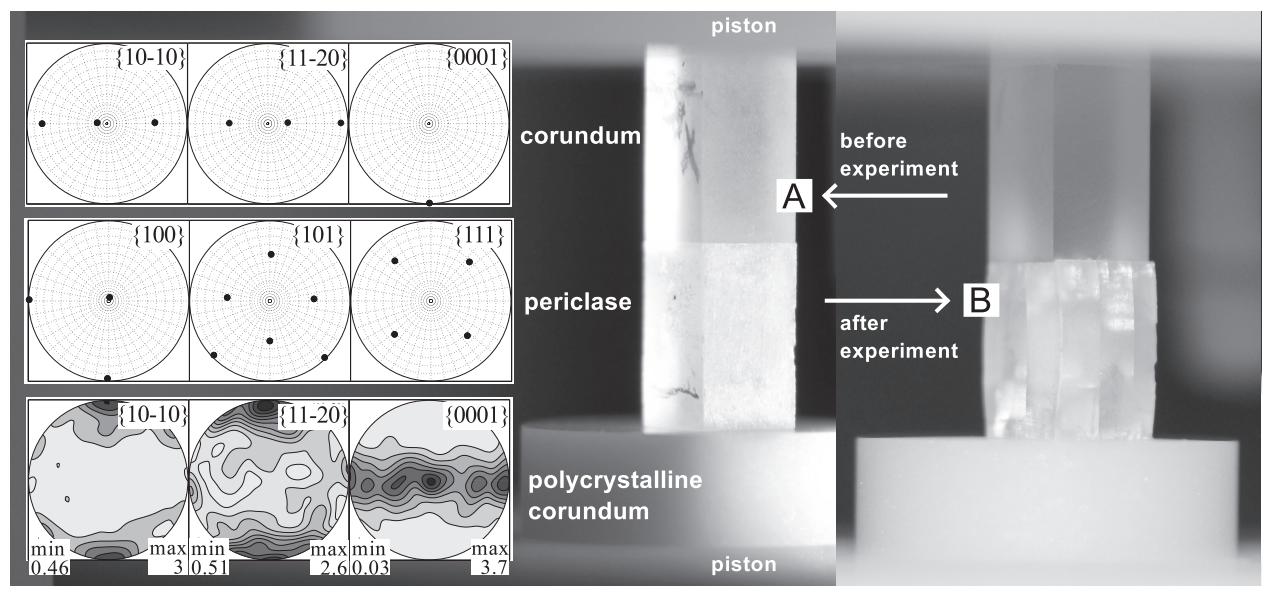

Fig. 1. Photographs showing the experimental set-up before (A) and after (B) the run CP28 (see table 1 for conditions). (A) Dimensions of both corundum and periclase single crystals are $3 \times 3 \times 5 \mathrm{~mm}$ and the polycrystalline corundum spacer is $10 \mathrm{~mm}$ in diameter and $3 \mathrm{~mm}$ in thickness. The pole figures (lower hemisphere equal area projection) show the initial orientations of corundum and periclase single crystals, and crystal preferred orientation of corundum in polycrystalline spacer.

others (2010). Synthetic, gem quality single crystals of corundum $\left(\mathrm{Al}_{2} \mathrm{O}_{3}\right)$ and periclase $(\mathrm{MgO})$ machined to quadrilateral prisms $(3 \times 3 \times 5 \mathrm{~mm})$ and a polycrystalline corundum spacer, all with known crystallographic orientations, were assembled in a stack (see fig. 1). The contact surfaces of the single crystals were polished with $0.5 \mu \mathrm{m}$ diamond paste and the contact surface of the polycrystalline corundum spacer was ground. During annealing, spinel $\left(\mathrm{MgAl}_{2} \mathrm{O}_{4}\right)$ reaction rims formed at the contacts between periclase and the single-crystal corundum and between periclase and the polycrystalline corundum (fig. 1). The contact surfaces of the two single crystals were oriented so that the close packed oxygen plane (0001) of corundum adjoins one of the cube planes (100) of periclase. The polycrystalline corundum spacers show crystallographic preferred orientation characterized by single girdle arrangement of the c-axes [0001] parallel to the contact to the periclase and hence to the periclase (100) plane (fig. 1). In a few runs, one half of the periclase face in contact with the corundum single-crystal was sputtered with platinum to obtain inert markers for tracing the position of the initial corundum-periclase contact (see for example Gardés and others, 2011).

The experiments were performed in dry atmosphere maintained by a constant argon gas flow at $0.1 \mathrm{MPa}$ pressure. Uniaxial loading was achieved by applying a constant weight acting perpendicular to the contact surfaces. Heating to the desired (maximum) temperatures and subsequent cooling occurred at $5{ }^{\circ} \mathrm{C} /$ min heating resp. cooling rates. Run duration, temperature, load, and the timing of loading were varied systematically to understand their effects on spinel rim growth (table 1 ). The high-load $(0.261 \mathrm{kN})$ and low-load $(0.026 \mathrm{kN})$ experiments correspond to normal stresses of 29 $\mathrm{MPa}$ and 2.9 $\mathrm{MPa}$, respectively, when calculated for a full contact area of $9 \mathrm{~mm}^{2}$. After the experiment, the contacts of single crystals and polycrystalline corundum were glued to maintain cohesion. The samples were put into epoxy and cut perpendicular to the crystal contact surfaces in a central position for preparation of polished thin sections. For final chemo-mechanical polishing for Electron Back-Scatter Diffraction (EBSD) analysis, a colloidal silica suspension with pH 9.2 to 10 (Köstrosol 3530) was used as polishing agent on a rotary polisher. Very thin carbon coating using a single 
TABLE 1

Physical conditions for different experimental runs

\begin{tabular}{|c|c|c|c|c|c|c|c|c|c|}
\hline \multirow{2}{*}{$\begin{array}{l}\text { load } \\
{[\mathrm{kN}]}\end{array}$} & \multirow{2}{*}{$\begin{array}{c}\text { temperature } \\
{\left[{ }^{\circ} \mathrm{C}\right]}\end{array}$} & \multirow{2}{*}{ loaded at } & \multicolumn{7}{|c|}{ time $[\mathrm{hrs}]$} \\
\hline & & & 5 & 10 & 20 & 23 & 40 & 80 & 160 \\
\hline 0.261 & 1350 & $\begin{array}{c}\max \\
\text { temperature }\end{array}$ & $\bar{~} \overline{\mathrm{V} 27(0)}$ & CP30(1/0) & $\bar{~} \mathrm{~V} 26(0)$ & & CP32(6/0) & $\overline{\mathrm{CP} 28(0)}$ & (CP31(8/3) \\
\hline 0.261 & 1350 & $\begin{array}{c}\text { room } \\
\text { temperature }\end{array}$ & & CP35(25/5) & CP34(22/8) & & & CP33(31/6) & \\
\hline 0.261 & 1300 & $\begin{array}{c}\text { room } \\
\text { temperature }\end{array}$ & & & & & & & CP38(26/4) \\
\hline 0.261 & 1250 & $\begin{array}{c}\text { room } \\
\text { temperature }\end{array}$ & & & & & & & CP37(19/6) \\
\hline 0.026 & 1350 & $\begin{array}{c}\text { room } \\
\text { temperature }\end{array}$ & & & & $\mathrm{CP} 40(0)$ & & & CP41(0) \\
\hline
\end{tabular}

Loading procedure indicates when the load was applied. Time refers to duration for which the desired (maximum) temperature was maintained. The index in parenthesis next to different runs indicates number of deformation twins detected after the experiment in the corundum crystal/number of twins hitting the corundum-periclase interface (see text).

carbon thread evaporated at $8 \mathrm{~cm}$ distance from the sample surface and at vacuum conditions of $<1.10^{-5}$ mbar established electrical conductivity for EBSD analysis.

\section{Crystal Orientation Imaging}

EBSD analyses were performed using a FEI Quanta 3D Field Emission Gun (FEG) instrument at the Center of Earth Sciences (University of Vienna, Austria). The FEG-SEM is equipped with an EDAX Digiview IV EBSD camera and an Apollo XV silicon drift detector for Energy Dispersive X-ray (EDX) spectrometry. EBSD and EDX data were collected simultaneously using the OIM Data Collection software v5.3.1 or v6.1.3. EBSD-analyses were performed at 11 to $13 \mathrm{~mm}$ working distance and a beam incidence angle of $20^{\circ}$ to the sample surface. Electron beam settings were $15 \mathrm{kV}$ accelerating voltage and about $2 \mathrm{nA}$ probe current in analytic mode (Scanning Electron Microscope aperture $1 \mathrm{~mm}$ ). An EBSD camera binning of $4 \times 4$ or $8 \times 8$ pixels has been used in order to achieve collection rates of 11 to 22 points per second during EBSD mapping. Hough settings of $1^{\circ}$ theta step size, a binned pattern size of 160 pixels, a $9 \times 9$ convolution mask (exception $13 \times 13$ used for scan V26) and a minimum peak distance of $15^{\circ}$ (exception $10^{\circ}$ used for scan V26) were applied for indexing 6 to 12 Hough peaks. In order to eliminate the influence of weak bands projected to marginal domains of the phosphorus screen a Rho-fraction of 80 to 90 percent has been used. EBSD mapping has been performed applying beam scanning at step sizes of 0.1 to 0.35 micrometers using an exposure time of 20 to 84 milliseconds.

The EBSD maps and pole figures were plotted in Matlab using the MTEX toolbox (Bachman and others, 2010). The crystallographic orientations and Orientation Distribution Function (ODF) data are presented in the lower hemisphere equal area projection pole figures. The ODF's were calculated using a de la Vallée Poussin kernel with appropriate half-width ranging between 6 and $10^{\circ}$ (Hielscher and others, 2010). The grains were reconstructed from EBSD data using the threshold misorientation angle of $2^{\circ}$ (Bachman and others, 2011).

\section{Mineral Chemical Analysis}

The chemical composition of spinel was determined using the FEG-EMPA Jeol JXA-8500F at GFZ Potsdam. The analytical conditions were $50 \mathrm{~nm}$ focus spot, $10 \mu \mathrm{A}$ 
beam current, $6 \mathrm{kV}$ accelerating voltage and 40 seconds counting time on the peak + 20 seconds counting the background signal on each side of the peak. The chemical profiles across the rims were carried out with $0.5 \mu \mathrm{m}$ step size and an excitation depth of $0.3 \mu \mathrm{m}$. A liquid nitrogen trap was used to reduce carbon contamination. TAP crystals were used for analyzing both $\mathrm{Al}$ and $\mathrm{Mg}$. Calibration was done using pure corundum and periclase crystals, respectively, from the sample. The CITZAF routine was applied for matrix correction.

\section{RESULTS}

\section{Deformation of Reactants}

Depending on the run conditions, both corundum and periclase crystals exhibit grain-internal deformation by various mechanisms. The corundum crystals largely retain their overall shape and dimensions. In several experimental runs, however, corundum shows considerable cracking and deformation twinning (figs. 2A and 2B). The twins occur on the rhombohedral planes $\{10-12\}$ and are associated with crack faces or the cracks originate at the intersections of twins (Heuer, 1966; Schmid and Harris, 1998). There is a remarkable inter-relation between twinning and cracking of corundum. In accordance with the results of previous studies (Scott and Orr, 1983; Schmid and Harris, 1998), samples showing intersection of differently oriented rhombohedral twins are characterized by extensive cracking, while samples with only a single orientation of rhombohedral twins are free of cracks. This suggests that the twinning in multiple systems induced cracking, which in turn may have caused further twinning. Table 1 shows the number of observed deformation twins in corundum related to the number of twins hitting the corundum-periclase interface, indicating that in the high-load experiments, deformation twinning and cracking is frequent when the load was applied at room temperature (table 1). In contrast the twins are sporadic or missing when the load was applied at maximum temperatures. Whenever twins and cracks in the corundum impinge on the contact between corundum and periclase, this produces topography of the interface, and void spaces and irregularities in the spinel rim thickness emerge (figs. 2B-2E).

The periclase crystals are characterized by more distributed internal deformation resulting in their barrel-shape appearance (fig. 1B). This barreling is, however, only seen in one direction perpendicular to shortening whereas it is inconspicuous in the other direction. The overall shortening of the periclase crystals varies from virtually undetectable strain in the short time $(5 \mathrm{hrs}$ ) experiment V27 to 17 percent shortening in the long time (160 hrs) experiment CP31. The internal strain is associated with the development of sub-grains (figs. $2 \mathrm{~F}$ and $2 \mathrm{G}$ ). The periclase crystals typically show through-going cracks oriented parallel to the applied force (figs. 1B and 2) and crosscutting the sub-grain boundaries (fig. 2F). These cracks probably result from thermal contraction during late stages of the experiments. The polycrystalline corundum spacers do not show any detectable changes in their dimensions nor deformation twins or cracks.

\section{Reaction Rim Geometry}

Rim thickness.-Spinel rims formed wherever corundum and periclase were in contact, that is at both the polycrystalline corundum-periclase and the single-crystal corundum-periclase contacts (fig. 2). The spinel rim thicknesses differ among individual experiments due to the differences in physical conditions and run durations (table 1, fig. 3). At the same time, large lateral variations in spinel rim thickness occur within individual experimental runs depending on the applied load and on the loading procedure. In the following text we mostly refer to the minimum thickness corresponding to the thinnest portion of the rim and to the maximum thickness 


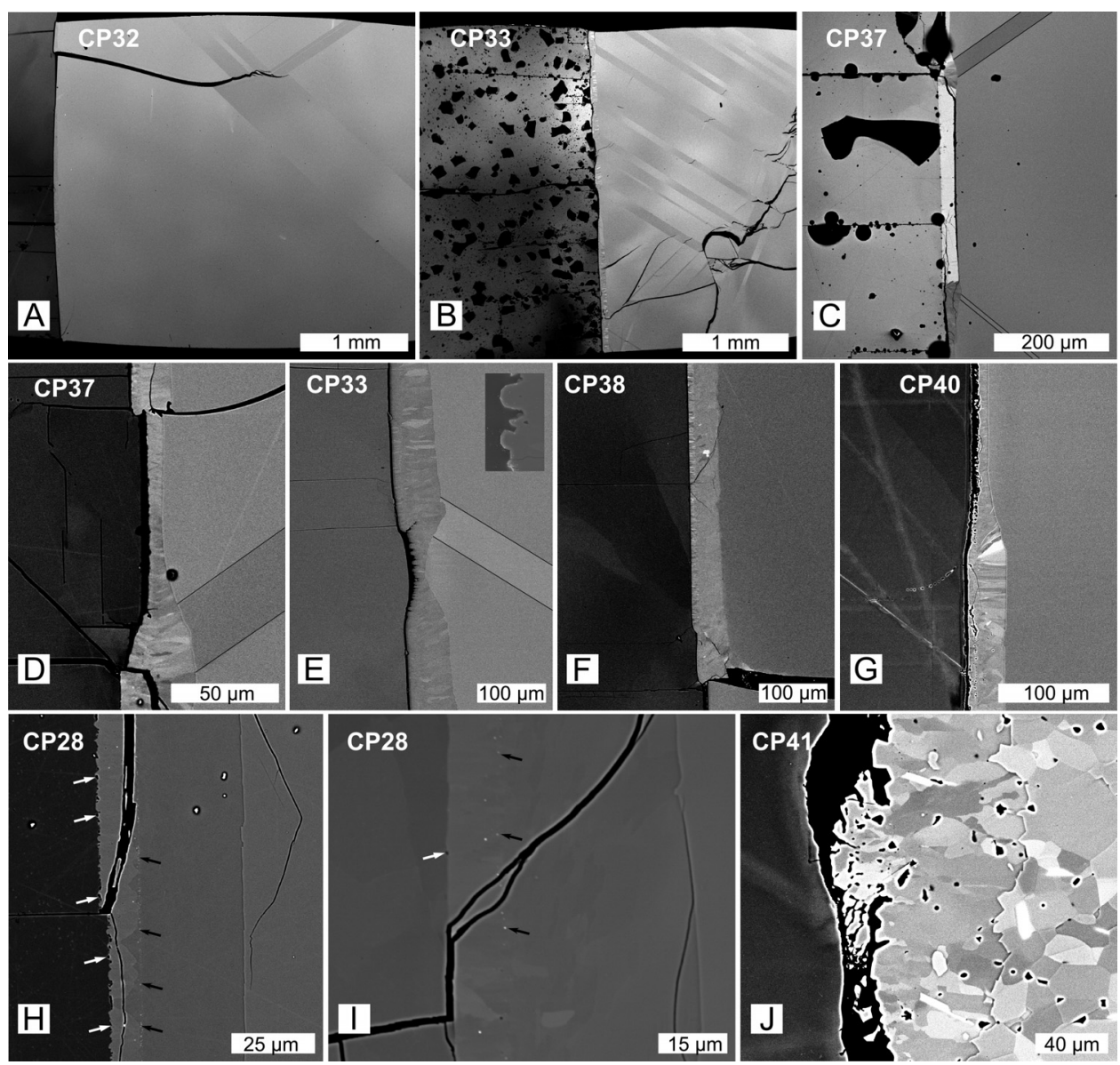

Fig. 2. Back-scattered electron (BSE) images showing the resulting spinel rims. The gray scale variations inside the rim correspond to distinct crystallographic orientation. Each image has corundum on the right side and periclase on the left side of the spinel rim. Sample names are also indicated in the images (see table 1 for experimental conditions). (A-E) show twinning and cracking of corundum crystals (for better visibility some twin boundaries are traced by black lines), (B-E) the effect of twinning and cracking in corundum on the spinel rim thickness, and (F-G) development of sub-grains in periclase. Detailed images of spinel rims formed at (H-I) single-crystal corundum-periclase and (J) polycrystalline corundum-periclase interfaces. The bright spots (marked by black arrows)inside the spinel rim in (H-I) are the platinum inert markers documenting the initial interface between corundum and periclase and the dark spots (marked by white arrows) decorating the spinel-periclase interface correspond to pores.

corresponding to the thickest portion of the rim characterized by relatively uniform thickness.

Lateral variations in rim thickness are most pronounced in the high-load roomtemperature loading experiments. They are related to the internal deformation of the single-crystal corundum including cracking and deformation twinning (table 1), which locally led to the loss of physical contact between the reactant phases. In these sections, the spinel rim thickness is lower than the average rim thickness (figs. 2A-2G), or the spinel rim may even be entirely missing, in cases where the physical contact between periclase and corundum was already lost during the initial stages of an experiment (figs. 2A and 2F). In several places void spaces formed between spinel and periclase (fig. 2G) and faceted spinel crystals grew into open-space towards the periclase (figs. 

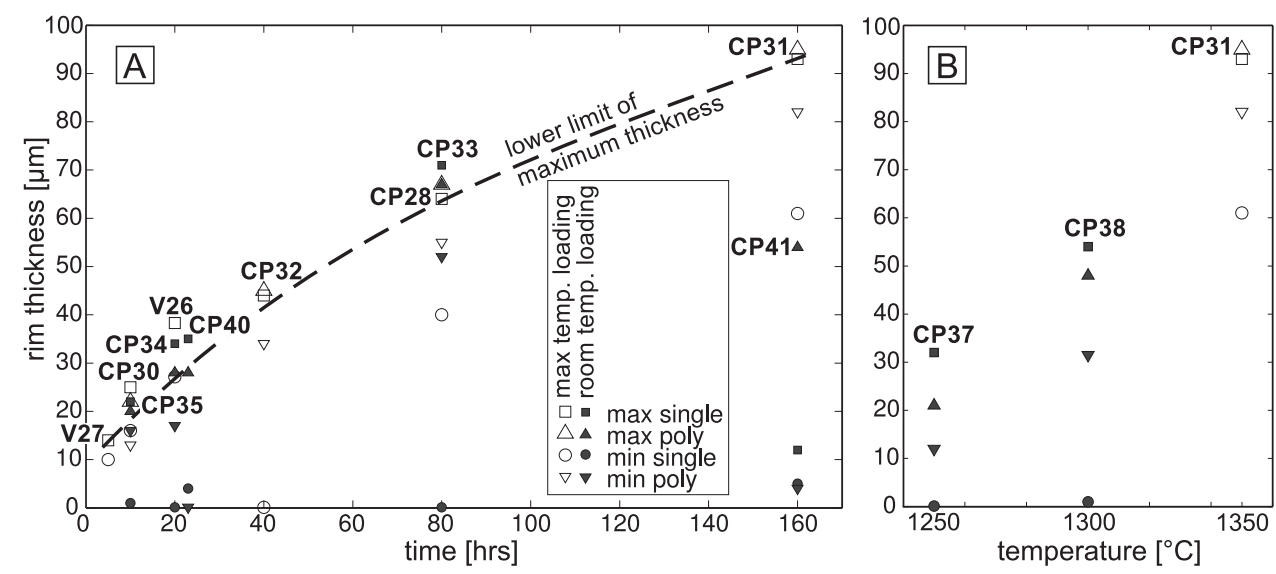

Fig. 3. Spinel rim thicknesses in different experimental runs shown against (A) time and (B) temperature. Maximum (plateau) and minimum thicknesses are shown for spinel rims developed at single-crystal corundum-periclase (single) and polycrystalline corundum-periclase (poly) interfaces. The labels of the different experimental runs are shown next to symbol for maximum thickness. Open and filled symbols are used for room-temperature and maximum-temperature loading experiments, respectively. For runs V26 and V27 only the rim thicknesses for single-crystal corundum-periclase couples are shown, because no polycrystalline corundum spacers were used in these experiments. Note that experiments CP40 and CP41 are the low-load experiments (see table 1).

$2 \mathrm{E}$ and $2 \mathrm{~J})$. The undisturbed portions of the periclase-corundum contact are characterized by relatively uniform thickness reaching the maximum values. In the high temperature loading experiments in which the contact between single-crystal corundum and periclase is mostly undisturbed by internal deformation of the corundum, the spinel rim thickness is relatively constant and varies between 65 to 100 percent of the maximum rim thickness. The rims that formed at the contacts between periclase and polycrystalline corundum in the high-load experiments show quite uniform thickness with less than 15 microns difference between the minimum and maximum thickness, irrespective of run duration, maximum rim thickness and loading procedure (fig. 3).

Contrastingly, in the low-load experiments, large lateral variations in rim thickness occur at both contacts of periclase and corundum despite the lack of internal deformation of the corundum. In sample CP40 (23 hrs, table 1), the rim formed at the contact between the single-crystal corundum and periclase shows two distinct but relatively uniform thicknesses (fig. $2 \mathrm{G}$ ) of $\sim 35$ microns, along one fifth of the reactive contact, and of 4 to 8 microns along the rest of the contact. The same contact in sample CP41 (160 hrs) shows relatively uniform but lower rim thickness of 6 to 12 microns. The spinel rims that formed at the contact between the polycrystalline corundum and periclase show much larger lateral variations in thickness for the low-load experiments as compared to the high-load experiments. Sample CP40 represents the only experimental run of all experiments where the rim thickness at this contact decreases to zero and the difference between maximum and minimum rim thickness is $\sim 27$ microns. At the same contact in sample CP41 the minimum rim thickness is only $\sim 4$ microns and the difference between the minimum and maximum thickness is $\sim 50$ microns (fig. 3).

Due to the pronounced lateral variations in rim thickness, the averaging of rim thickness across the entire width of a sample is not meaningful. Hence, when comparing different experimental runs as well as the two different reactive contacts in one run, that is periclase against single-crystal and polycrystalline corundum, we only refer to the thickest portions of the rims with relatively uniform thickness (the maximum thickness in fig. 3). In the high-load experiments, the maximum rim 
thickness increases with time (fig. 3A) and for a given run duration it also increases with increasing temperature (fig. 3B). In the high-load room-temperature loading experiments, the rims formed at the contacts with single-crystal corundum have somewhat higher maximum rim thicknesses than those that formed at the contacts between polycrystalline corundum and periclase (fig. 3). In the high-load maximumtemperature experiments, this relationship seems to be identical for short durations (below $\sim 40 \mathrm{hrs}$ ), however it is opposite for longer durations (table 1; fig. 3).

In the low-load experiments, the evolution of rim thickness with time is complicated. When comparing the maximum rim thicknesses of the short (CP40) and long (CP41) low-load experiments, they show higher thickness for polycrystalline corundum and periclase contacts in the long experiment but higher thickness for singlecrystal corundum and periclase contacts in the short experiment (fig. 3). Furthermore, the maximum rim thicknesses for both contacts in the short experiment are comparable with the high-load experiment CP34 of similar duration, while the maximum rim thicknesses in the long experiment are rather low in comparison to the high-load experiment CP31 (fig. 3).

Reaction rim structure.-Spinel rims formed at the contacts between polycrystalline corundum and periclase commonly comprise small fragments of corundum and inherit the porosity of the polycrystalline corundum (fig. 2J). Furthermore, small spinel grains frequently occur at triple junctions within the polycrystalline corundum. In contrast, spinel that formed from a single-crystal corundum is confined to the immediate rim, and the porosity inside the rim is rather scarce.

Locally in the rims formed between single-crystal corundum and periclase, the abrupt transitions in spinel microstructure recognized in the vicinity of corundum twins document the presence of cracks (fig. 2E). These cracks, however, do not crosscut individual spinel grains and therefore most likely represent inherited structures, which originally developed in corundum and were later overgrown/healed by spinel. Similar cracks with identical orientation with respect to deformation twins occur elsewhere in the corundum crystals (for example fig. 2B). Scarce fragments of corundum enclosed by spinel were locally identified next to these healed cracks.

The initial corundum-periclase interface is traced by the inert platinum markers and is now situated within the spinel rims. Therefrom the volumetric proportions of the spinel rim grown in the directions of periclase and corundum, have been determined in the range of 1:3 to 1:3.75 independent of local stress concentrations or cracking (figs. 2H and 2I). These ratios are in good agreement with previous observations (Sieber and others, 1996; Watson and Price, 2002; Götze and others, 2010; Keller and others, 2010).

Reaction interfaces. - The contacts between the reactant phases and spinel are commonly affected by the formation of contact-parallel cracks related to unloading of the experiments. These cracks are most prominent at the periclase-spinel interface so that this contact is never preserved towards polycrystalline corundum and is preserved only rarely towards single-crystal corundum (figs. 2H-2J). In contrast, the contacts between spinel and polycrystalline corundum are always preserved and the contacts between spinel and single-crystal corundum are mostly preserved (figs. 2D-2I). In places, where the periclase-spinel interface is preserved, sub-micrometer sized pores are aligned along large portions of these interface segments (fig. $2 \mathrm{H}$ ), in some cases, however, the porosity may be rather scarce (fig. 2I), depending on the topotactic relations between spinel and periclase (see below). The periclase-spinel contacts are straight although some roughness is observed on the sub-micrometer scale due to the presence of the pores (compare figs. 2H and 2I). The contacts between polycrystalline corundum and spinel are corrugated (fig. 2J). In contrast, the contacts between single-crystal corundum and spinel are relatively smooth (figs. 2H and 2I). 


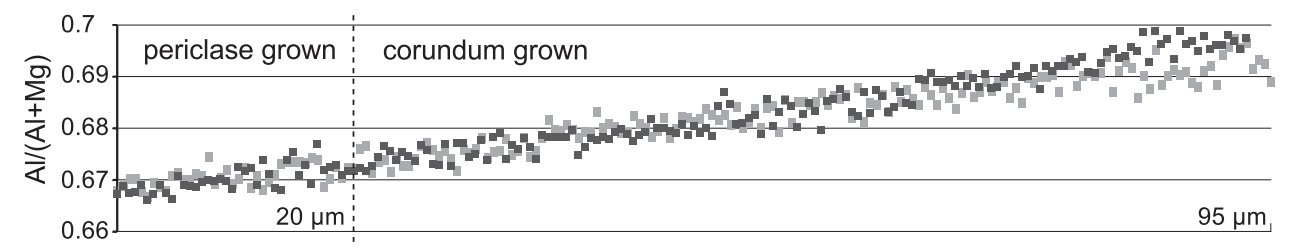

Fig. 4. Two chemical profiles across the spinel rim from the longest experiment CP31 (table 1). The two profiles marked by the black and gray squares are located 150 microns from each other and correspond to Profiles 1 and 2, respectively, in figure 8B. The dashed line marks the portions of the spinel rim that grew towards periclase and corundum, respectively.

\section{Spinel Chemistry}

The composition of spinel was only analyzed in reaction rims with single-crystal corundum as the reactant phase. The spinel shows systematic change of composition from close to stoichiometric with a molar ratio of $\mathrm{Al}_{2} \mathrm{O}_{3} / \mathrm{MgO}$ in the range of 0.98 to 1.00 at the periclase-spinel interface to more aluminous with $\mathrm{Al}_{2} \mathrm{O}_{3} / \mathrm{MgO}$ up to 1.15 in the longest experiment (CP31) at the spinel-corundum interface (fig. 4). The composition profiles across the rim are characterized by a continuous change in the $\mathrm{Al}_{2} \mathrm{O}_{3} / \mathrm{MgO}$ proportions (fig. 4) and do not reveal any jumps or changes in slope. Corundum and periclase at the contact with spinel are stoichiometric within the accuracy of the microprobe analyses.

\section{Spinel Texture and Microstructure}

Spinel topotaxy.- In the spinel rims that formed at the contacts between singlecrystal corundum and periclase, the spinel grains show topotactic orientation relations to both reactant phases. Three types of topotactic relations have been recognized in the context of spinel rim growth by Keller and others (2010): (i) full topotaxy of cubic spinel to cubic periclase, (ii) partial topotaxy of cubic spinel to trigonal corundum with two of the $\{111\}_{\text {spil }} \|(0001)_{\text {cor }}$ and six of the $\{101\}_{\text {spi }} \|\{10-10\}_{\text {cor }}$, and (iii) axiotaxy of spinel to corundum with two of the $\{111\}_{\text {spi }} \|(0001)_{\text {cor. }}$. The partial topotaxy (ii) and axiotaxy (iii) to corundum is satisfied by two different spinel orientations, which are related through the spinel twin law (twin plane (111), equivalent to $60^{\circ}$ rotation around the [111] axis). Identical topotactic relations were observed in all our experiments. Which one of these relations prevails in a specific sample depends on the loading conditions. Full topotaxy between spinel and periclase (i) and partial topotaxy between spinel and corundum (ii) prevail in the high-load maximum-temperature loading experiments (fig. 5A) as well as in the low-load room-temperature loading experiments (table 1). In contrast, full topotaxy between spinel and periclase (i) combined with axiotaxy between spinel and corundum (iii) prevail in the high-load room-temperature loading experiments (table 1 ).

Keller and others (2010) found that the topotaxy of spinel relative to periclase dominates in the portion of the rim that has grown into the direction of periclase while topotaxy and axiotaxy of spinel relative to corundum dominate in the portion that has grown into the direction of corundum. On the one hand, such relationships are most common also in our experiments (figs. $2 \mathrm{H}$ and $5 \mathrm{~A}$ ). On the other hand, we further recognized two additional cases where spinel topotaxy either to corundum or to periclase dominates the entire rim (figs. 2C and 2I, and 5B and $5 \mathrm{C}$ ). The portions of the rim with spinel topotaxy to periclase form a layer comprised essentially of a single grain, which typically consists of slightly misoriented domains with sub-grain/grain boundaries perpendicular to the reaction front (fig. 5A). In contrast, the layer with spinel topotaxy to corundum show complex inter-growths of the two twin orientations 

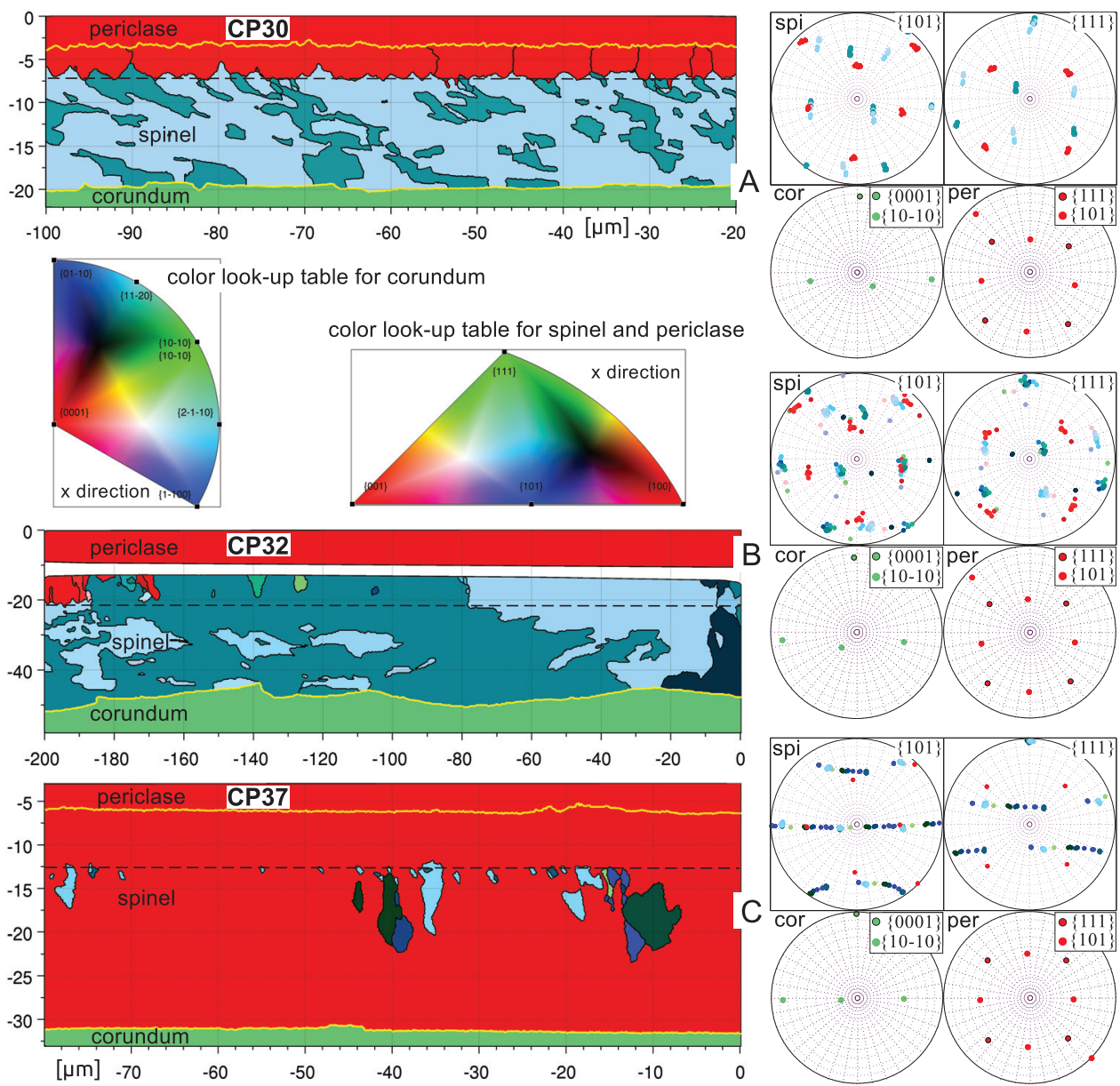

Fig. 5. EBSD maps with reconstructed grains and the pole figures (lower hemisphere equal area) for corundum, periclase and spinel document the following topotactic relations: (A) full topotaxy to periclase in the rim portion that grew towards periclase and partial topotaxy to corundum in the rim portion that grew towards corundum in sample CP30, (B) partial topotaxy to corundum across the entire rim in sample CP32, and (C) full topotaxy to periclase across the entire rim in sample CP37. The grain maps and grain orientations in the pole figures are colored according to the inverse pole figure color scheme marking the position of the horizontal (x-axis) direction with respect to the crystallographic orientation of the individual grains. Points in the pole figures represent integrated orientation of individual grains. The thick yellow solid lines highlight the boundaries between the different phases. The black dashed lines indicate the boundaries between spinel rim portions that grew towards periclase and corundum, respectively.

of spinel. The orientations of the twin boundaries are mostly parallel or perpendicular to the reaction front (fig. 5B), however an oblique preferred orientation has also been observed in parts of the rim (for example in fig. 5A). The domains with spinel axiotaxy to corundum are characterized by the development of palisade grains with preferred orientation of grain boundaries perpendicular to the reaction front (fig. 2E). The boundary between the two texturally distinct layers (with topotaxy to periclase and corundum, respectively) is usually highly irregular with zigzag pattern with the tips of the layer with topotaxy to periclase reaching the initial corundum-periclase contacts (figs. $2 \mathrm{H}$ and $5 \mathrm{~A}$ ). The sub-grain/grain boundaries in the layer with topotaxy to periclase geometrically coincide with the thinnest portions of this layer (fig. 5A). 


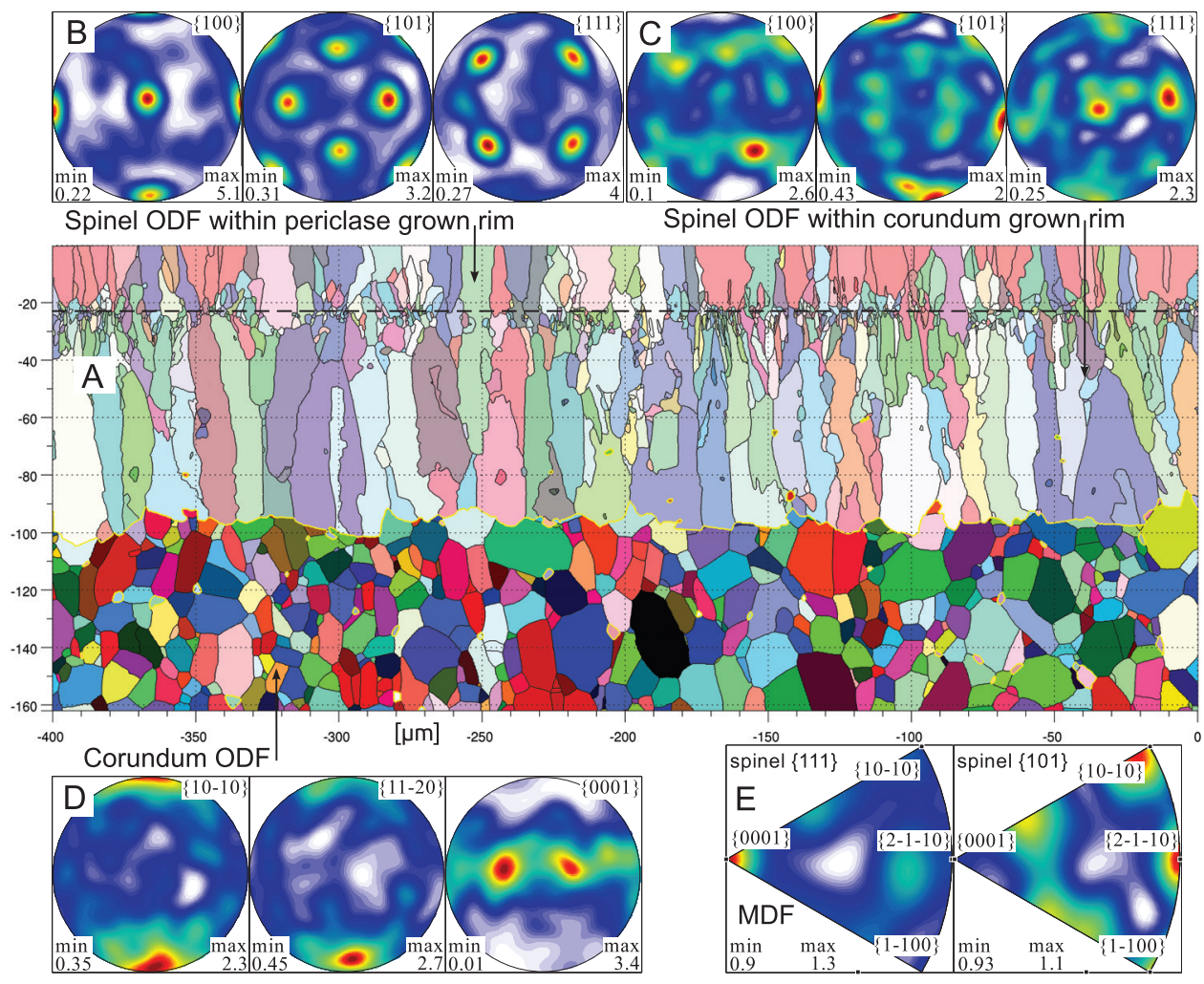

Fig. 6. Spinel reaction rim grown at the interface between polycrystalline corundum and periclase (sample CP31). (A) Corundum (solid colors) and spinel (pastel colors) grains: the color scheme in the grain map follows figure 5 . The thick yellow solid line highlights boundaries between corundum and spinel: note the presence of corundum within spinel and vice versa. The black dashed line shows the boundary between spinel rim portions that grew towards periclase and corundum, respectively. (B) Orientation distribution function (ODF) for spinel that grew towards periclase, (C) ODF for spinel that grew towards corundum and (D) ODF for corundum. (E) Correlated Misorientation Density Function (MDF) between spinel and corundum grains in contact. The $\{111\}$ and $\{101\}$ planes of spinel are plotted into inverse pole figure diagrams of corundum on the basis of the misorientations between the two minerals.

In the reaction rims that formed at the contacts between polycrystalline corundum and periclase, the identification of spinel topotaxy is complicated by the multiple crystallographic orientations of the polycrystalline corundum (fig. 6A). On the other hand, the orientation distribution function (ODF) within the rim portion that grew into the direction of periclase clearly documents spinel topotaxy to periclase (compare periclase orientation in figs. 1 and 6B). Similarly, a weak topotaxy of spinel to corundum within the rim portion that grew into the direction of polycrystalline corundum may be suspected from comparing the ODF's of spinel and corundum (fig. 6C and 6D). The crystallographic relationship between neighboring spinel and corundum grains can be evaluated by means of the correlated misorientation distribution function (MDF), which describes the probability of certain misorientation between two grains, multiple grains, ODF's or crystallites with different symmetries (Morawiec, 1997). The corundum and spinel grains in contact show weak correlation of the $(111)_{\text {spi }} \|(0001)_{\text {cor }}$ as well as $\{101\}_{\text {spi }} \|\{10-10\}_{\text {cor }}$ and $\{101\}_{\text {spi }} \|\{11-20\}_{\text {cor }}$ planes suggesting partial topotaxy (ii) and axiotaxy (iii) cases (fig. 6E). In these rims, the spinel microstructure is characterized by the development of palisade grains elongated 
perpendicular to the reaction front (fig. 6A). The position of the initial corundumpericlase contact is typically marked by numerous small spinel grains.

Deviation from perfect topotaxy and axiotaxy.-The spinel with full topotaxy to periclase shows small angular deviations $\left(<4^{\circ}\right)$ with respect to the orientation of periclase (figs. 7A, 7B, 7D and 7E). These deviations do not show any systematic lateral change along the rim and are related to slightly misoriented domains bounded by sharp orientation transitions. These domains may be considered as sub-grains or separate grains depending on the degree of misorientation (compare figs. 7A and 7B). The misorientation axes between individual measurements from spinel with topotaxy to periclase do not show any systematic relationship to the crystallographic directions of spinel, they are, however, mostly oriented parallel to the reaction interface (fig. 7B). The spinel grains with topotaxy to periclase do not show any systematic changes in orientation or orientation scattering in the direction perpendicular to the reaction front.

Spinel grains with topotaxy to corundum typically show perfect match of the $(111)_{\text {spi }} \|(0001)_{\text {cor }}$ and $\{101\}_{\text {spi }} \|\{10-10\}_{\text {cor }}$ planes near the corundum-spinel interface. Further away from the reaction front and towards the initial periclase-corundum contact they show slight deviation from this topotactic relationship (for example fig. 7C). This trend is accompanied by an increase of internal misorientation within individual spinel grains from the spinel-corundum interface towards the location of the initial periclase-corundum contact (fig. 7B). Similarly to the spinel with topotaxy to periclase, the misorientation axes for the spinel with topotaxy to corundum do not show any systematic relationship to the crystallographic directions of spinel (fig. 7B). As compared to the spinel with topotaxy to periclase, the spinel with topotaxy to corundum shows larger scatter of the misorientation axes, however, they still tend to be oriented parallel to the reaction interface (fig. 7B).

The axiotaxy of spinel to corundum is characterized by the lack of the $\{101\}_{\text {spi }} \|\{10-10\}_{\text {cor }}$ relation while maintaining the axial $[111]_{\text {spi }} \|[0001]_{\text {cor }}$ relationship. In some rims, few axiotactic grains occur in the vicinity of twin grains with partial topotaxy (ii) to corundum (figs. 7A and 5C). These axiotactic grains are typically elongated perpendicular to the reaction interface and they either maintain contact with corundum or in some cases they are completely surrounded by spinel with partial topotaxy (ii) to corundum. When axiotactic grains occur further away from the initial corundum-periclase interface, they show perfect orientation match between $[111]_{\text {spi }} \|[0001]_{\text {cor }}$ and lack any internal misorientation (compare figs.7A, 7B and 7C).

The prevalence of the axiotactic relation to corundum is characteristic for experiments with frequent deformation twinning in corundum that is in the high-load room-temperature loading experiments (see table 1). Sample CP33 (fig. 7D) shows a typical example of spinel axiotaxy to corundum in the portion of the rim that grew into the direction of corundum. Similarly to the rims formed at the contacts between polycrystalline corundum and periclase, the microstructure in domains dominated by spinel with axiotaxy to corundum is characterized by palisade grains elongated perpendicular to the reaction front (compare figs. 6A and 7D). The axiotactic spinel grains are characterized by clusters of similar orientations (figs. 7E and 7G) which are arranged along small circles defined by rotation around the $[111]_{\text {spil }} \|[0001]_{\text {cor }}$ topotactic axis. Similarly to rims dominated by partial topotaxy, also the orientation match between $[111]_{\text {spil }} \|[0001]_{\text {cor }}$ is much better close to the corundum-spinel contact, whereas it nearly disappears at the initial corundum-periclase contact (fig. 7F). Furthermore, the orientation clusters of the axiotactic spinel are well defined near the corundum-spinel interface and become scattered towards the initial corundumpericlase contact (fig. 7E). Small angular deviations among individual spinel grains within these clusters observed near the corundum-spinel interface (fig. 7G) resemble 

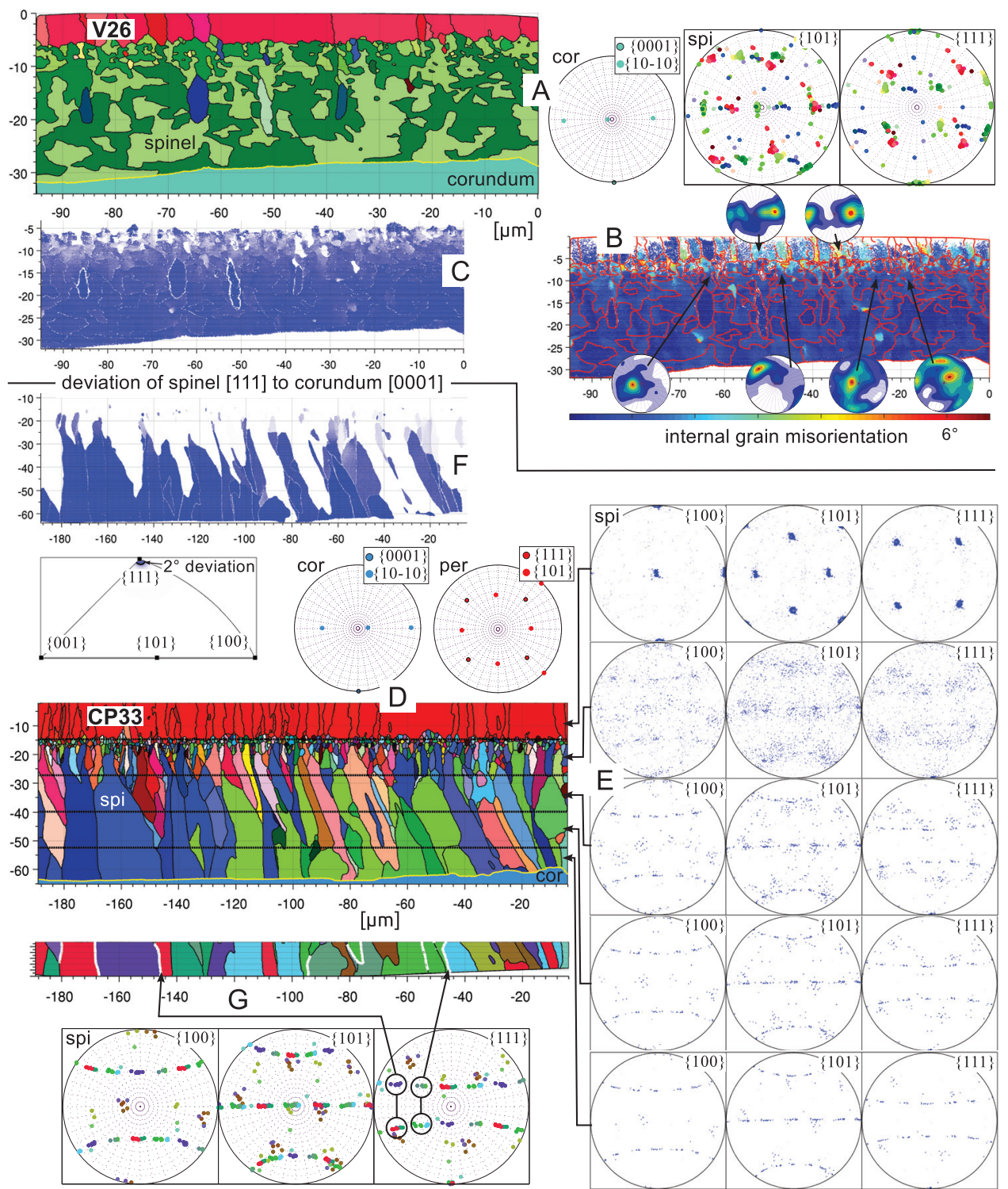

Fig. 7. Two examples of spinel axiotaxy to corundum: partial topotaxy dominated sample V26 (A, B, C) and axiotaxy dominated sample CP33 (D, E, F, G). (A and D) EBSD maps with reconstructed grains and pole figures for corundum and spinel (A) and corundum and periclase (D). The color scheme in the grain maps and pole figures follows the color coding scheme of figure 5 , the thick yellow solid line highlights boundaries between the individual phases. (B) Internal misorientation of individual spinel grains including the pole figures of the misorientation axes for six selected grains. The contour maxima in these pole figures vary between 2.5 and 5 times the uniform density distribution. ( $\mathrm{C}$ and $\mathrm{F}$ ) Maps showing the angular deviation of spinel [111] with respect to corundum [0001]. The increasing deviation is manifested by decreasing opacity of the blue color according to the color scheme in the inverse pole figure diagram below the two maps. (E) Spinel crystallographic orientations plotted separately for five horizontal strips (indicated by the black dashed lines in (D)) demonstrate changes in spinel texture across the rim. A random selection of one tenth of the orientation data points (approx. 6000 out of 60000) from each stripe was plotted into the pole figures. (G) The EBSD map and pole figures for spinel at the contact with corundum. Points in the pole figures represent integrated orientation of individual grains. A different color coding scheme was used to demonstrate the lack of spatial correlation among grains with similar orientations. The thick solid white lines represent spinel twin boundaries with $60^{\circ}$ misorientation. 
misorientations between sub-grains and a host grain. However, the grains characterized by small misorientations are usually not in contact, and on the contrary, the neighboring grains have frequent $60^{\circ}$ misorientation twin boundaries (thick white lines in fig. 7G). Thus the axiotactic orientation clusters rather document the existence of multiple twin systems (two systems of twins are marked by black circles in the $\{111\}$ pole figure in fig. 7G). Moreover, the axiotactic twin grains in some cases alternate with grains, which seem to inherit their orientation from periclase (red-pink grains in fig. $7 \mathrm{D}$ and brown grains in fig. 7G). Thus the palisade grains microstructure likely resulted from growth of variously oriented spinel grains in the direction perpendicular to the reaction interface.

Relationship between reactant deformation and spinel texture and microstructure.-The internal deformation of the reactant phases may affect the resulting texture and microstructure of the spinel rim. The deformation of periclase is typically associated with lattice distortion and local development of sub-grains. Sample CP28 documents progressive $7^{\circ}$ rotation of the periclase lattice around an axis that is parallel to the reaction interface (fig. $8 \mathrm{~A}$ ). The neighboring spinel with topotaxy to periclase mostly maintains the original orientation (before rotation) of the periclase. At the same time, few small spinel grains in contact with the rotated portion of periclase mimic its new (rotated) orientation (fig. 8A). These grains typically occur at some distance from the initial corundum-periclase interface suggesting that the internal rotation of the periclase developed during the later stages of the experiment.

Corundum deformation twins impinging on the corundum-periclase contact produce orientation scattering and complex crystallographic orientation relations as well as complicated microstructural patterns of spinel (figs. 8B-8D). Scattering of spinel lattice orientations due to deformation twinning in corundum may have been produced by two main mechanisms. Firstly, spinel grains have formed so that they lack a topotactic relationship to either one of the reactant phases but show clear (111) twin relationship to the neighboring topotactic spinel grains. As the topotaxy to corundum is satisfied by two spinel orientations related by twinning along one of the $\{111\}$ planes, the non-topotactic twins are formed via occupying another of the remaining $\{111\}$ twin planes (compare orientations of non-topotactic twins marked by colored open circles with light and dark blue orientation clusters of topotactic twins in the spinel $\{111\}$ pole figure in fig. 8B). The second mechanism, leading to orientation scattering, is by the formation of grains with partial topotaxy to the corundum twins (fig. 8C and D), which very likely reflects nucleation of spinel on the corundum twins. Once this partial topotaxy has been established, it can be maintained even if the spinel grain gets into contact with corundum having the initial orientation (fig. 8D). Sample CP38 documents both scattering mechanisms in one rim (fig. 8D). Initially, spinel grains with topotaxy to a corundum twin (orange and light green grains in fig. 8D) are formed at the intersection of the corundum twin with the initial corundum-periclase contact. At a later stage of rim growth, spinel grains with twin relation to spinel with topotaxy to corundum of initial orientation (dark green and purple grains in fig. 8D) are formed at the contact with the corundum deformation twin. In sample CP33, some of the spinel grains at the contact with the corundum deformation twin maintain the topotaxy to the corundum twin (fig. 8C).

Furthermore, samples affected by corundum deformation twinning are marked by the frequent development of axiotaxy to corundum and palisade microstructure (figs. 8C and 8D). The multiple orientations of the palisade grains due to axiotaxy are combined with some orientation scattering as previously shown in figure 7E. Moreover, it is interesting to note that sample CP38 shows domains with either partial topotaxy or axiotaxy of the spinel to corundum, which are bounded by sharp lateral transitions (fig. 8D). 

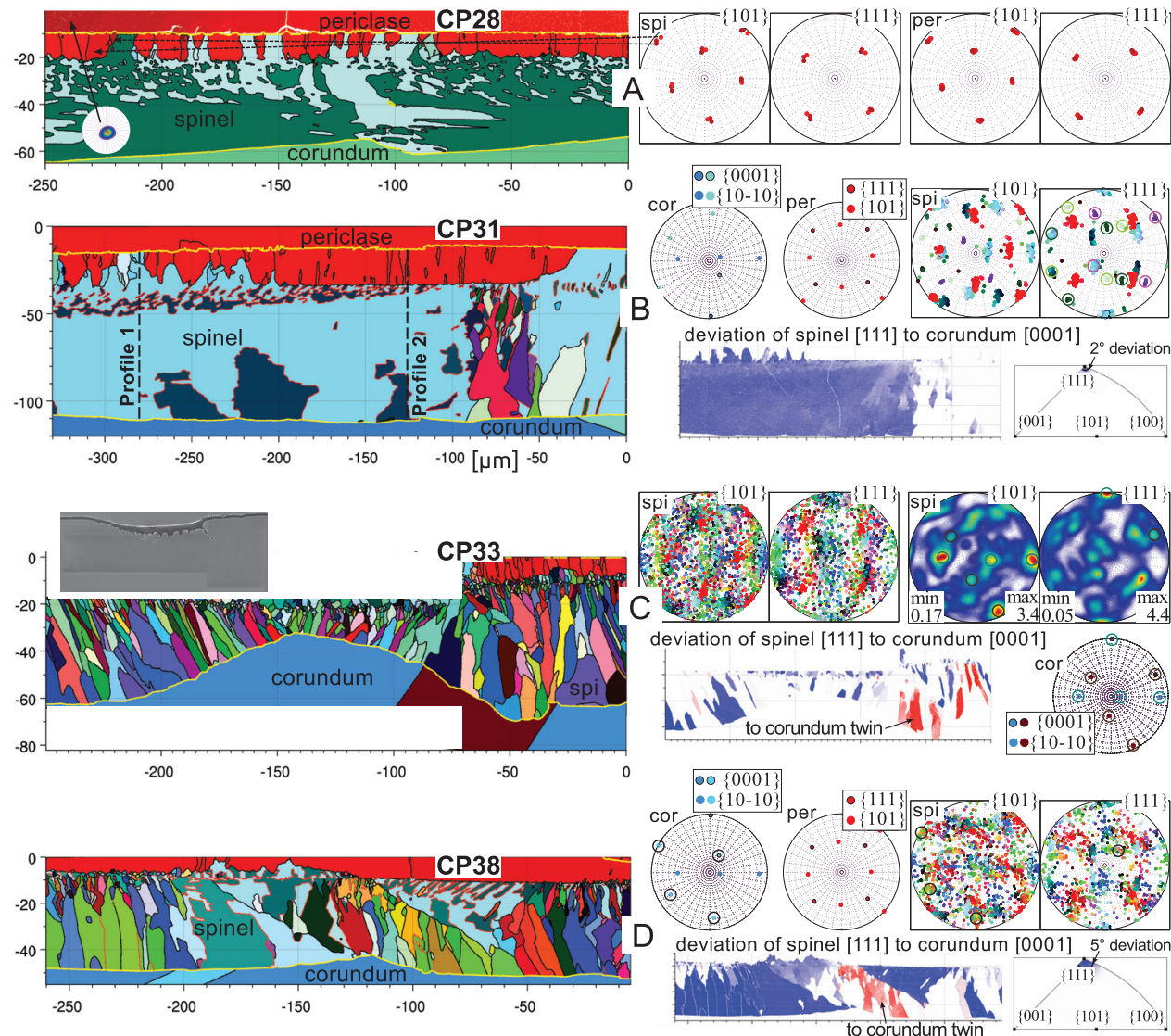

Fig. 8. Effects of reactant deformation on spinel texture and microstructure: (A) lattice distortion of periclase and (B-D) corundum deformation twinning. The points in the pole figures represent integrated orientations of individual grains. The color scheme in the EBSD maps and pole figures follows figure 5 , the yellow solid line highlights boundaries between individual phases. (A) The right to left color change of periclase in the EBSD map corresponds to a $7^{\circ}$ lattice rotation around a sub-horizontal axis (pole figure inset). The orientations of three selected spinel grains in the pole figures demonstrate the tendency of spinel to inherit the local (rotated) orientation of periclase. (B) The deformation twin in corundum (bottom right of the EBSD map) marks the change in the spinel microstructure and texture. The black dashed lines labeled Profile 1 and Profile 2 in the EBSD map correspond to location of chemical profiles presented in figure 4 . The topotactic relations of spinel to corundum characterized by orientation match between $[111]_{\text {spil }} \|[0001]_{\text {cor }}$ are presented in the map to the left. The colored open circles in the spinel $\{111\}$ pole figure demonstrate the twin relationship of the non-topotactic spinel grains to spinel twins with topotaxy to corundum (see text). The thick red boundaries in the EBSD maps in (B) and (D) mark the spinel twin boundaries. (C) EBSD map with corundum deformation twin and spinel palisade grains. The spinel pole figures manifest the texture scattering. The topotactic relationship of spinel to deformation twins in corundum is manifested by local maxima in the ODF diagrams (highlighted by brown open circles) to the left and by the deviation from topotaxy map below. This map shows angular deviation of spinel [111] with respect to corundum [0001] of the initial (blue grains) and twin (red grains) orientations. Increasing deviation is manifested by decreasing opacity of blue and red colors according to the color scheme in the inverse pole figure diagram shown in (D). (D) The EBSD map, pole figures and the deviation from topotaxy map indicates that various spinel textures and microstructures can be found in a single rim.

\section{DISCUSSION}

\section{Effects of Uniaxial Load on Rim Growth}

Depending on the applied load and the loading procedure, and depending on whether single-crystal corundum or polycrystalline corundum was used as a starting 
material, large variations in spinel rim thickness were obtained in individual runs. In this respect, our results contrast with perfectly uniform spinel rim thicknesses characteristic for the isotropic stress experiments of Watson and Price (2002), which were performed at pressures and temperatures in the range of 1 to $4 \mathrm{GPa}$ and 1200 to $2000{ }^{\circ} \mathrm{C}$. These authors reported identical rim thicknesses irrespective of whether the reactants were single-crystals or polycrystalline. In our uniaxial stress experiments, we obtained rims of non-uniform thickness (fig. 2) and thickness difference between rims formed adjacent to polycrystalline corundum and those adjacent to corundum singlecrystals (fig. 3).

The effect of corundum deformation-void space opening.-The non-uniform thicknesses are characteristic mainly for the high-load room-temperature loading experiments. The thinnest portions of the rim typically occur at places where cracks and deformation twins in corundum impinge on the reaction interface (fig. 2). Such an impingement leads to the bending of the contact surfaces and local loss of contact. Due to the uniaxial load on the sample, stress concentrations are associated with any irregularities at the reaction interface. The loss of contact and associated opening of void space between reacting crystals occurred at different stages of the experiments. The lack of spinel adjacent to cracks that cut corundum at the high angle with respect to the reaction rim (fig. $2 \mathrm{~A}$ and $2 \mathrm{~F}$ ) indicates that cracking and associated void space opening occurred early. In contrast, the reaction interface next to the corundum deformation twins shows either lack of spinel or local decrease of rim thickness (figs. 2B, 2E and 8C) indicating that in the latter case the opening of a void space between spinel and periclase occurred somewhat later during the experiment. These later voids are typically associated with growth of faceted spinel crystals into open space towards the direction of periclase (figs. $2 \mathrm{E}$ and $2 \mathrm{G}$ ). The corundum deformation twinning, however, also occurred in the early stages of our experiments as demonstrated by the topotaxy of spinel to corundum twins near the initial corundum-periclase contact (figs. 8C and 8D). Therefore at least in some cases, the twin induced bending of the corundum reactive surface does not directly lead to the opening of void space. Instead, the stress heterogeneity due to twinning produce a "tight," "high quality" reaction contact at one side of the corundum twin and a "less tight," "low quality" contact on the other side.

The spinel-forming reaction occurs via inter-diffusion of $3 \mathrm{Mg}^{2+}$ and $2 \mathrm{Al}^{3+}$ as indicated by spinel growth at both reaction fronts towards periclase and corundum (for example Koch and Wagner, 1936; Rossi and Fulrath, 1963; Hesse and others, 1995; Keller and others, 2010). Underlying this reaction, there is a variety of elementary processes, which may potentially be rate limiting: 1) breaking of bonds in the reactant phases, 2) transfer of $\mathrm{Mg}^{2+}$ across the periclase-spinel interface and of $\mathrm{Al}^{3+}$ across the corundum-spinel interface, 3) rearrangement of the oxygen sub-lattice at both reaction interfaces and 4) recombination of $\mathrm{Al}^{3+}, \mathrm{Mg}^{2+}, \mathrm{O}^{2-}$ to form spinel at both reaction interfaces. Where the physical contact between periclase and corundum or between periclase and spinel is lost, spinel growth by simple rearrangement of the oxygen sub-lattice is not possible. In this case, $\mathrm{O}^{2-}$ must be transported in addition to $\mathrm{Mg}^{2+}, \mathrm{Al}^{3+}$ to facilitate faceted growth of spinel into void space. The diffusion of oxygen is probably substantially slower (Ando and Oishi, 1974) than $\mathrm{Mg}$ and $\mathrm{Al}$ diffusion, and the necessary transport of oxygen at places with no physical contact between spinel and the reactant phases slows down the overall transformation rate at such contacts. The overall transformation rate is thus expected to be enhanced in places with tight contacts as compared to places with less tight contacts or void spaces between spinel and periclase. The lateral variation in rim thickness may be further accentuated by the effect of the +7 percent bulk volume increase that is associated with the transformation of corundum plus periclase into spinel at $1350^{\circ} \mathrm{C}$ and $1 \mathrm{bar}$ (Fiquet 
and others, 1999). Due to the overall volume increase, enhanced reaction at the segments of the reaction interfaces with tight physical contact will further enforce the tight contacts, leading to a positive feedback between tight contact and reaction progress. Consequently, small differences in the reaction progress along the reaction interface will become more pronounced with time leading to the lateral variations in spinel rim thickness. In the case of charge balanced inter-diffusion of $\mathrm{Mg}^{2+}$ and $\mathrm{Al}^{3+}$ the transformation bulk strain is -14 percent at the spinel-periclase reaction front, and it is +16 percent at the spinel-corundum reaction front. This might explain why loss of physical contact and the opening of void space is only observed at the spinel-periclase reaction front and does not occur on the side of corundum.

The effect of periclase deformation-void space closure.-The plasticity of periclase is an important factor leading to reduction of a void space, which may be opening along the reaction interface. Two slip systems, the $\{110\}\langle 1-10\rangle$ and $\{001\}\langle 1-10\rangle$, have been recognized in high temperature deformation experiments of periclase (Copley and Pask, 1965; Haasen, 1985). Periclase compressed along the [100] direction, as in our case, has two suitably oriented planes for activation of dislocation glide. These are two of the $\{110\}$ planes oriented $45^{\circ}$ from the compression stress axis (fig. 1A), which have high Schmid factor $(0.5)$ for the $\{110\}\langle 1-10\rangle$ slip. In our experiments, dislocation glide along this slip system is indicated by the barrel shape of periclase observed in the single section perpendicular to both of these $\{110\}$ planes (fig. 1B). The $\{110\}\langle 1-10\rangle$ slip in periclase has not been investigated at the temperatures of our experiments. Linear extrapolation of the existing mechanical data (Haasen, 1985) to higher temperatures suggests $\sim 2.3 \mathrm{MPa}$ as a critical resolved shear stress for the activation of $\{110\}\langle 1-10\rangle$ slip at $1350{ }^{\circ} \mathrm{C}$. In our experiments, the two suitably oriented $\{110\}$ planes were exposed to shear stresses of $14.5 \mathrm{MPa}$ in the high-load experiments and $1.45 \mathrm{MPa}$ in the low-load experiments, above and below the critical shear stress for activation of $\{110\}\langle 1-10\rangle$ slip, respectively. The expected limits on dislocation glide in periclase in our low-load experiments could account for large lateral variations in spinel rim thickness in these experiments, which do not show any evidence for internal deformation in corundum. Thus once the lateral variations in rim thickness are established due to enhanced reaction at the segments of the reaction interfaces with tight contacts, the opening void space cannot be effectively reduced by plasticity of periclase. On the other hand, local stress concentrations and stress increase associated with irregularities at the reaction fronts may locally induce periclase plasticity as demonstrated for example by the development of sub-grain boundaries (see fig. 2G).

The concept of asperity yielding (Bowden and Tabor, 1964) can be used for estimating the critical contact surface area at which plastic yielding in periclase may occur in our low-load experiments. In their model Bowden and Tabor (1964) assumed that yielding occurs at the contacting asperities until the contacting area is just sufficient to support the normal load. This relationship can be expressed as

$$
\mathrm{N}=\mathrm{p} * \mathrm{Ar}
$$

where $\mathrm{N}$-represents load, p-material strength and Ar-contacting asperity area. Changing the point of view, we may also assume that the contacting area can be reduced until plastic yielding in one of the phases in contact occurs. In our experiments neither corundum nor spinel show evidence for plasticity thus only yielding of periclase is sought. For the $2.3 \mathrm{MPa}$ critical resolved shear stresses at $1350{ }^{\circ} \mathrm{C}$ (Haasen, 1985) and 0.5 Schmid factor for the two $\{110\}$ glide planes, the axial stress needed to induce dislocation glide in periclase is $4.6 \mathrm{MPa}$. This suggests that the effective contact surface in our low-load experiments could be reduced via opening of void space between reacting crystals to at least 63 percent of its original area before the periclase yields plastically. The possibility to reduce the contact area of our reaction interface into just 
a few points maintaining the "high quality" tight reaction contact needs to be taken into consideration when interpreting the rim thicknesses formed under low-load conditions. Moreover, it is possible that some of the studied sections do not crosscut the segments with tight contact and hence the resulting rim thickness may be dramatically underestimated. We suppose that such an "erroneous" sample cut can explain the fairly thin rims in our 160 hrs, low-load experiment CP41 where no contact between spinel and periclase was observed (fig. 3). To avoid these effects in future work, the low-load experimental samples should be first observed with 3D computed tomography or only the sections preserving contacts to both periclase and corundum should be interpreted.

\section{Deformation of Corundum}

It is interesting to note that the strength of corundum under compression along the c-axis in our experiments is different when the load was applied at room temperature and in the maximum-temperature loading experiments. In the high-load experiments, the corundum deformation twins occur only sporadically when the load was applied at maximum temperatures while they are frequent when the load was applied at room temperature (see table 1). It has been demonstrated that with increasing temperature the c-axis compressive strength of corundum decreases dramatically between 20 to $600{ }^{\circ} \mathrm{C}$ and then remains at $\sim 2$ percent of the room-temperature strength (Schmid and Harris, 1998). Under c-axis compression at lower to intermediate temperatures, corundum typically yields via rhombohedral twinning, which at temperatures $>600{ }^{\circ} \mathrm{C}$ requires only $26.5 \mathrm{MPa}$ axial stress (Scott and Orr, 1983; Schmid and Harris, 1998). The available c-axis compression experiments on corundum were, however, only performed up to temperatures of $1100{ }^{\circ} \mathrm{C}$ (Scott and Orr, 1983). At higher temperatures, corundum deforms via $(0001)\langle 11-20\rangle$ basal slip, the $\{1-210\}\langle 10-10\rangle$ prism plane slip and the $\{10-11\}\langle-1101\rangle$ pyramidal slip (Heuer and Castaing, 1985; Heuer and others, 1998). However, the c-axis compression, as in our case, is only suitable for activating pyramidal slip which, on the other hand, is less common and was only demonstrated at high stresses and elevated temperatures above $1500{ }^{\circ} \mathrm{C}$ (Snow and Heuer, 1973; Heuer and Castaing, 1985). This indicates that corundum in our high-load experiments should deform exclusively by rhombohedral twinning. The lack of twins in some of our high-load and $1350{ }^{\circ} \mathrm{C}$ experiments documents that the c-axis strength above $600{ }^{\circ} \mathrm{C}$ may not remain constant but could increase above $1100{ }^{\circ} \mathrm{C}$. Indeed, the four point flexure experiments with the c-axis parallel to the tensile axis in the outer arc and compression axis in the inner arc show gradual decrease in strength from room temperature to $1000{ }^{\circ} \mathrm{C}$ followed by slight increase in strength towards $1400^{\circ} \mathrm{C}$ (Schmid and Harris, 1998). Although the four point flexure experiments are not directly comparable to compression experiments, the predicted increase in the c-axis compressive strength towards higher temperatures might well explain our results. A possible explanation for this hardening effect can be related to the introduction of some dislocations into the corundum crystal lattice which act as obstacles for twinning (Castaing and others, 2002).

\section{Evolution of Spinel Texture/Microstructure with Reaction Progress}

The question arises whether the observed spinel texture/microstructure is a growth-related feature or whether it could have been modified by subsequent deformation and recrystallization. The two dominating topotactic orientations of spinel characterized by [100] or [111] axes parallel to the compressive stress are suitable to activate $\{110\}\langle 1-10\rangle$ and $\{111\}\langle 1-10\rangle$ slip, respectively. However, in the light of the literature on spinel deformation (for example Donlon and others, 1998), this scenario seems unlikely, because activation of these slip systems requires orders of magnitude higher 
stresses than those applied in our experiments. The observed internal misorientation within the spinel grains is thus most likely a growth feature. Recrystallization may be suspected in places where spinel grains with axiotaxy to corundum occur within domains that are dominated by grains with partial topotaxy to corundum (fig. 7A). These grains typically show little internal misorientation as compared to the grains in their immediate vicinity. Based on the notion that the geometrically necessary dislocations, associated with grain-internal orientation gradients and increasing the free energy of the respective grain, can be eliminated by transformation into a plain, dislocation free grain, a recrystallization origin may be suspected for these grains. Similar reasoning applies to grains with little internal misorientation and with partial topotaxy to corundum, which occasionally occur within domains that are dominated by topotaxy to periclase (fig. 8B). The fact that these grains show better topotactic match between the $[111]_{\text {spi }}$ and $[0001]_{\text {cor }}$ compared to the surrounding grains, even though they do not appear to be in contact with corundum (figs. $7 \mathrm{C}$ and $8 \mathrm{~B}$ ), is, however, not compatible with a recrystallization origin. When these grains formed they most probably were in contact with corundum, and once formed they kept growing perpendicular to the reaction front until a more energetically favorable orientation took over. We thus conclude that the observed spinel texture and microstructure were coined during spinel growth.

Topotaxy via oriented nucleation and selective growth.-The evolution of the spinel rims may be summarized as follows: 1) spinel nucleated on periclase and/or corundum inheriting the crystallographic orientation of either one of the reactants, 2) neighboring nuclei of similar orientation coalesced into single grains and 3) the growth of grains towards one or both reactants lasted until the end of the experiment or until a grain with more favorable orientation took over. The irregular shape of the boundary between the domains with topotaxy to periclase and with topotaxy to corundum, respectively (for example figs. 5A and 7A), nicely demonstrates some of the aspects of this evolution. Only the tips of the domains with topotaxy to periclase touch the initial corundum-periclase contact (figs. $2 \mathrm{H}, 5 \mathrm{~A}$ and $7 \mathrm{~A}$ ). This suggests that the onset of reaction rim formation most of the grains nucleated on corundum and comparatively few, isolated grains nucleated on periclase. Subsequent growth of the grains with partial topotaxy to corundum led to coalescence and finally resulted in the growth of spinel into both directions, that is towards periclase and towards corundum. The grains with topotaxy to periclase grew towards periclase and subsequently coalesced as demonstrated by the slightly misoriented domains (sub-grains/grains) within spinel layer with topotaxy to periclase (figs. 7A and 7B). Very likely these sub-grains/grains reflect growth from several nuclei with slightly different orientation. Similarly, the coalescence of slightly misoriented nuclei may explain the relatively high internal misorientation of grains with topotaxy to corundum in the vicinity of the initial corundum-periclase contact (fig. 7B).

The fact that grains were generated from nuclei with slight misorientations may indicate that nucleation took place on a reaction interface that was densely populated with dislocations with the burgers vector pointing out of the interface plane and with steps or ledges. It has been argued based on TEM observations that during the incipient stages of spinel growth the orientation of the reaction interface slightly deviates from the orientation of the lattice planes of the reactant phases (Sieber and others, 1997b). In such case, the reaction front is comprised of segments, where the orientation of the lattice planes is slightly off the orientation of the reaction interface. Nucleation of spinel on different segments will thus produce grains with slight misorientation and subsequent coalescence of such grains may explain the observed grain internal orientation gradients. 
During the later stages of reaction rim growth, the character of the misfit dislocations at the reaction interfaces changes to those with burgers vectors within the interface plane (Sieber and others, 1997b). In such case, large sections of the reaction front may be perfectly parallel to the lattice planes providing stable conditions for topotactic growth. Indeed, the topotactic relation between spinel and corundum improves with increasing distance from the initial reaction contact. In contrast, the initially established deviation between periclase and spinel lattices is maintained during the whole experiment (for example fig. 7B). With this respect, it is important to note that the spinel-corundum interface is parallel to close packed oxygen planes while the spinel-periclase interface is not. Therefrom it seems that the reinforcement of high quality topotaxy is easier if the reaction front is parallel to the close packed oxygen planes. Moreover, the spinel-corundum interface is smooth compared to the spinel-periclase interface, which in places follows the crystal facets of small spinel grains advancing towards periclase (fig. $2 \mathrm{H}$ ) and thus again tends to become parallel to the close-packed oxygen $\{111\}$ planes marked by pyramidal facets.

The analysis of texturally and microstructurally complex rims indicates that spinel tends to form topotactic orientation relations by selective growth or by nucleation of favorably oriented grains also during the later stages of reaction rim growth. Selective growth of grains with axiotaxy or topotaxy to corundum is observed in domains, which are dominated by axiotactic spinel and in rims that formed at the contacts between polycrystalline corundum and periclase. In these situations typically a palisade microstructure is developed and numerous small grains can be identified at the initial corundum-periclase contact with random orientation relations to the reactant phases (figs. 6A and 7D). Only a few of these grains develop into palisade grains and, as demonstrated by rims that formed at the contacts between single-crystal corundum and periclase, these are typically grains with axiotactic relationship to corundum (compare figs. 7D and 7F). The weak topotaxy and axiotaxy of spinel to the neighboring corundum grains in the rims formed at the contacts between polycrystalline corundum and periclase further corroborates selective growth of grains with topotactic relationship.

Nucleation of grains with more favorable topotactic orientation during the later stages of reaction rim growth has been observed in several cases. Most commonly this is found when spinel with topotaxy to corundum occupies portions of rim that grew from periclase. In such places, the topotaxy to periclase is still the preferred case at the spinel-periclase reaction front and nucleation of grains with topotaxy to periclase may occur within these domains far from the initial corundum-periclase contact (for example figs. 8A, 8B and 8D). Similarly, when the periclase crystal becomes distorted, new spinel grains nucleate at the spinel-periclase reaction front that mimic the orientation of the distorted periclase (fig. 8A). In places, the axiotactic grains nucleate on grains with partial topotaxy to corundum, which show deviation from the perfect orientation match between $(111)_{\text {spi }}$ and $(0001)_{\text {cor }}$. In this case, the growth of an axiotactic grain maintaining stable $(111)_{\text {spi }} \|(0001)_{\text {cor }}$ relationship at the spinelcorundum reaction interface is preferred. If, however, the grains with partial topotaxy to corundum fulfill the (111) spil $(0001)_{\text {cor }}$ criterion they are more stable and suppress the formation of new axiotactic grains (for example fig. 7A). This is probably due to the fact that not only the close packed oxygen planes but also the closest packed directions in spinel and corundum are parallel in the case of partial topotaxy.

In addition, it is interesting to note that nucleation of grains with favorable topotaxy may also be enhanced by stress concentrations such as those in the vicinity of corundum deformation twins (figs. 8B-D). On one side of the twin characterized by "tight" reaction contact, the boundary between the spinel layers with orientation relation to corundum and with topotaxy to periclase, respectively, is straight (figs. 8B 
and $8 \mathrm{D}$ ) indicating equal nucleation of grains with topotaxy to both reactants at this portion of the initial periclase-corundum contact. In contrast, the less tight reaction contacts on the other side of the twin are marked either by the absence of spinel with topotaxy to periclase (figs. $8 \mathrm{~B}$ and $8 \mathrm{C}$ ) or by its nucleation only during later stages of rim growth (fig. 8D). With this respect it is worthy to note that also the topotaxy of spinel to the corundum deformation twins is established right at the moment of or shortly after the deformation twinning took place. Later on, when the twins become inactive, the more favorable topotaxy to the corundum with initial orientation takes over (fig. 8D).

\section{Structure of the Reaction Interfaces}

The inter-diffusion of $3 \mathrm{Mg}^{2+}$ and $2 \mathrm{Al}^{3+}$ accounting for the chemical mass transfer underlying rim growth occurs within a framework of relatively immobile, non-diffusing oxygen (Koch and Wagner, 1936). Reaction rim growth implies that the oxygen sub-lattice is reconstructed across the moving reaction interfaces. Starting from an incoherent contact between corundum and periclase, the first atomic layers of spinel probably form islands (nuclei) along the reaction interface inheriting the orientation of either one of the reactant phases, depending on where exactly these first layers of spinel form. In our experiments several situations were observed: 1) nucleation of spinel on corundum led to a semi-coherent contact between spinel and corundum and an incoherent contact between spinel and periclase, 2) nucleation of spinel on periclase led to a semi-coherent contact between spinel and periclase and to an incoherent contact between spinel and corundum, and 3) nucleation of spinel on both corundum and periclase led to the formation of semi-coherent contacts between spinel and both reactants.

The semi-coherent contact between the hexagonal close packed corundum and the face centered cubic spinel lattices is characterized by an $(111)_{\text {spi }} \|(0001)_{\text {cor }}$ and $\{110\}_{\text {spi }} \mid\{10-10\}_{\text {cor }}$ relationship bringing into parallelism two close packed oxygen planes with pseudohexagonal symmetry. The misfit between the two lattices is given by the oxygen-oxygen distance in the closest packed direction within the close packed planes that is $0.2857 \mathrm{~nm}$ for [110] spinel and $0.275 \mathrm{~nm}$ for [10-10] corundum (see Rossi and Fulrath, 1963). After correction for thermal expansion and spinel stoichiometry (Yoo and others, 1991; Fiquet and others, 1999), the positive misfit of spinel with respect to corundum changes from 3.9 percent for stoichiometric spinel down to 3.8 percent for non-stoichiometric $\left(\mathrm{Al}_{2} \mathrm{O}_{3} / \mathrm{MgO}=1.15\right.$ for the longest experiment CP31) spinel at the corundum-spinel contact. In contrast, the semi-coherent contact between the fcc lattices of spinel and periclase with cube to cube relationship shows a negative misfit of spinel with respect to periclase of -4.8 percent (see also Sieber and others, 1996, 1997a). The lattice mismatch is typically accommodated by sets of parallel interfacial dislocations giving rise to a semi-coherent interface (for example Sieber and others, 1997a).

In our case, the growth of magnesio-aluminate spinel on a periclase substrate is characterized by a negative misfit, which is accommodated by line defects with their Burgers vectors lying within the reaction interface plane (Sieber and others, 1996, 1997a). Therefore the propagation of the spinel-periclase interface is most likely governed by climb of the misfit dislocations. The climb of the misfit dislocations at the spinel-periclase interface into the periclase corresponds to the progression of $\mathrm{MgAl}_{2} \mathrm{O}_{4}$ spinel lattice half-planes into the periclase. This occurs by the emission of cation and anion vacancies from the misfit dislocation into the periclase immediately ahead of the advancing spinel-periclase reaction front. With the progressing transformation of periclase this may lead to the accumulation of vacancies and eventually to their oversaturation resulting in the nucleation of pores. Such pores are prone to being dragged along with the advancing reaction interface giving raise to pinning and 
non-planar geometry of the reaction front (Petrishcheva and Renner, 2005). Pinning of an advancing reaction front by misfit dislocations was previously documented in thin films (Hesse and others, 1995). Indeed in our experiments, pores are typically aligned along those segments of the spinel-periclase contact where spinel is topotactic to periclase (fig. $2 \mathrm{H}$ ) and a semi-coherent spinel-periclase interface can be expected. In contrast, voids are practically absent at those segments of the spinel-periclase interface, where the spinel shows orientation relation to the corundum, and the spinelpericlase interface is incoherent. An incoherent interface serves as an efficient source or sink for vacancies suppressing local oversaturation with respect to vacancies, and pore formation does not occur. In addition, the formation of pores at the spinelpericlase interface requires efficient removal of excess $\mathrm{Mg}^{2+}$ and $\mathrm{O}^{2-}$ from the reaction interface and thus requires some mobility of oxygen. This may be related to the so-called Kirkendall effect (Kirkendall, 1942) assuming that $\mathrm{Mg}^{2+}$ is more mobile in spinel than $\mathrm{Al}^{3+}$ (Whitney and Stubican, 1971). The flux of magnesium may be enhanced with respect to the flux that is allowed by charge balanced inter-diffusion of $\mathrm{Mg}^{2+}$ and $\mathrm{Al}^{3+}$ if $\mathrm{O}^{2-}$ diffuses along with $\mathrm{Mg}^{2+}$ from the spinel-periclase interface to the spinel-corundum interface. It is this combined cation and anion diffusion that generates Schottky defects in the source region and allows for the nucleation of voids at the spinel-periclase interface, which would be impossible, if the interface was supersaturated with respect to $\mathrm{MgO}$.

Two mechanisms for transformation of the hcp oxygen lattice of corundum into the fcc oxygen lattice of spinel have been speculated so far: 1) systematic tilt of the spinel lattice out of the exact topotactic relation towards more favorable coherency and motion of interfacial ledges either along or normal to the interface (Carter and Schmalzried, 1985; Hesse and others, 1995) or 2) glide of partial dislocations with out of plane burgers vectors observed in similar transformations in metals (Christian, $1951)$. With our topotaxy, both mechanisms would lead to small tilts $\left(\sim 2^{\circ}\right)$ of spinel (111) planes with respect to the (0001) planes of corundum around a rotation axis close to the $\langle 110\rangle$ close-packed direction, because both are characterized by identical burgers vectors (Carter and Schmalzried, 1985; Li and others, 1992; Sieber and others, 1997a). This contrasts with our results, which despite relatively high internal misorientations of the spinel grains with topotaxy to corundum show non-systematic orientation relationship between lattice directions in spinel and misorientation axes obtained by comparing orientations of close-packed planes and directions in corundum and spinel. An alternative scenario, based on the lack of systematic tilt, assumes that the $(111)_{\text {spill }} \|(0001)_{\text {cor }}$ and $\{110\}_{\text {spi }} \|\{10-10\}_{\text {cor }}$ topotactic growth of spinel from corundum occurs by only a slight shift in the oxygen positions which changes the oxygen stacking from $\mathrm{ABAB}$ to the cubic ABCABC (Rossi and Fulrath, 1963). In such case, the interstitial $\mathrm{Al}^{3+}$ ions crossing the interface neither create nor destroy lattice sites. This mechanism may apply to our case, in particular, when the interface reaction is no longer rate limiting and the misfit dislocations can climb in the diffusion-controlled regime (Sieber and others, 1997b). Furthermore, the spinel with topotaxy to corundum shows improving topotactic match away from the initial corundum-periclase contact (fig. 7C), which may be related to the decreasing lattice misfit with increasing non-stochiometry of spinel (see above).

Diffusion-controlled growth is further corroborated by the fact that the spinel rims are largely independent of whether a segment of the reaction interface is semi-coherent or incoherent. With the exception of slightly irregular contacts between spinel with topotaxy to periclase and periclase, the other contacts of topotactic and axiotactic spinel with both reactants are rather smooth and planar (fig. 2). This contrasts with highly irregular contacts between corundum and spinel with the lack of topotaxy in the polycrystalline corundum-periclase rims (figs. 2J and 6). 
Reaction rim growth of polycrystalline magnesio-aluminate spinel at periclasecorundum interfaces was studied experimentally at temperatures of 1250 to $1350{ }^{\circ} \mathrm{C}$ and under uniaxial load of 0.026 and $0.26 \mathrm{kN}$ per $9 \mathrm{~mm}^{2}$ of initial contact area. Two different loading procedures were applied including immediate application of the load followed by heating to the desired maximum temperature and application of the load only after the desired maximum temperature had been reached. Immediate loading in the high-load experiments lead to localized deformation of corundum by twinning and cracking, which in turn disturbed the physical contact at the reaction interface producing segments of the reaction interface with tight physical contact and others with loose contact between the reactant phases. Reaction rim growth was strongly enhanced at the sections with tight contact and lagged behind or did not occur at the sections with loose contact, which resulted in considerable lateral variations in rim thickness. Even greater lateral variations in rim thickness recorded in the low-load experiments are associated with the lack of periclase plasticity, which in the high-load experiments ensures good physical contact at the reaction interface. Reaction rims with relatively uniform thickness were produced if loading was applied after the maximum temperature had been reached. From our experiments we conclude that the loading conditions as well as the loading procedure are crucial for the growth rate and the microstructure and texture evolution of the spinel reaction rims.

Regarding the topotactic relations between spinel and the two reactant phases we confirm earlier observations. Three types of topotactic relations are observed including full topotaxy between spinel and periclase, partial topotaxy with $(111)_{\text {spi }} \|(0001)_{\text {cor }}$ and $\{101\}_{\text {spi }} \|\{10-10\}_{\text {cor }}$, and axiotaxy with $(111)_{\text {spil }} \|(0001)_{\text {cor }}$ between spinel and corundum. The spinel rims are comprised of domains where one type of topotaxy prevails. Usually but not exclusively, domains with topotaxy to periclase grew towards periclase and are in contact with periclase and domains with topotaxy to corundum grew towards corundum and are in contact with corundum rendering the respective reaction interfaces semi-coherent. Domains with full topotaxy between spinel and periclase can be found in all run products, irrespective of the loading conditions and procedure. With respect to the topotactic relations between spinel and corundum, the partial topotaxy is the preferred case for low-load and for high-load maximumtemperature loading experiments, whereas the axiotaxy prevails for high-load roomtemperature loading experiments. Domains with axiotaxy between spinel and corundum are typically characterized by a palisade microstructure resulting from intergrowth of spinel grains with different orientation being dominated by multiple growth twins related by spinel-twin law.

The evolution of spinel microstructure and texture is only related to growth as no supportive evidence for recrystallization and plastic deformation in spinel has been found. Selective growth and oriented nucleation are identified as the main mechanisms underlying the inclination towards topotactic relations between spinel and the reacting phases. In the case of oriented nucleation on corundum, the $(111)_{\text {spi }} \|(0001)_{\text {cor }}$ and $\{101\}_{\text {spi }} \|\{10-10\}_{\text {cor }}$ partial topotaxy is preferred. On the other hand, if the $[111]_{\text {spi }}$ becomes deviated from $[0001]_{\text {cor }}$, the axiotactic $(111)_{\text {spi }} \|(0001)_{\text {cor }}$ nucleation takes place and prevails over the already established topotaxy even during later growth stages. The oriented nucleation on periclase may occur at any stage of the experiment, however it seems to be enhanced at places where stress concentration and tight contacts of the reaction interface are expected. Similarly, the spinel grains with topotaxy to corundum deformation twins nucleate in the moment of twinning when a tight contact with the twin is expected.

Considerable orientation gradients within individual spinel grains are ascribed to coalescence of slightly misoriented nuclei. The systematic decrease of grain-internal 
misorientation from the initial periclase-corundum interface towards the spinelcorundum reaction front in domains with topotaxy to corundum is ascribed to a gradual change in the organization of the misfit dislocations at the spinel-corundum reaction interface, probably grading from prevalence of Burgers vectors pointing out of the interface plane to Burgers vectors with only in-plane components. Such a transition implies an initially high interface mobility due to glissile motion of the misfit dislocations to lower interface mobility due to the necessary dislocation climb. The presence of pores along the semi-coherent sections of the spinel-periclase interface and contemporaneous lack of porosity at the incoherent portions is ascribed to the efficient annihilation of vacancies that are emitted by the advancing spinel-periclase reaction interface at the incoherent portions of the interfaces whereas this does not occur at the semi-coherent portions of the interface.

\section{ACKNOWLEDGMENTS}

This work was supported by the German Science Foundation (DFG) grant AB 314/3-1, which pertains to the FOR 741 DFG research group. The salary to PJ was partly covered by the Ministry of Education, Youth and Sports of the Czech Republic Research Plan MSM0021620855. GH acknowledges the Austrian Science Foundation (FWF) grant I471-N19 as part of the Research group FOR741-DACH. An anonymous reviewer is thanked for proposing improvements to the manuscript. L. Götze and S. Zertani are thanked for performing some of the experiments. S. Gehrmann is thanked for pre- and post-treatment of the experimental material.

\section{REFERENCES}

Ando, K., and Oishi, Y., 1974, Self-diffusion coefficients of oxygen ion in single crystals of $\mathrm{MgO} \mathrm{nAl}_{2} \mathrm{O}_{3}$ spinels: Journal of Chemical Physics, v. 61, n. 2, p. 625-629, http://dx.doi.org/10.1063/1.1681938

Bachmann, F., Hielscher, R., and Schaeben, H., 2010, Texture analysis with MTEX-Free and open source software toolbox: Solid State Phenomena, v. 160, p. 63-68, http://dx.doi.org/10.4028/www.scientific. net/SSP.160.63

- 2011, Grain detection from 2d and 3d EBSD data-specification of the MTEX algorithm: Ultramicroscopy, v. 111, n. 12, p. 1720-1733, http://dx.doi.org/10.1016/j.ultramic.2011.08.002

Bowden, F. P., and Tabor, D., 1964, The friction and lubrication of solids: part II: Oxford, Oxford University Press, $261 \mathrm{p}$.

Carter, C., and Schmalzried, H., 1985, The growth of spinel into $\mathrm{Al}_{2} \mathrm{O}_{3}$ : Philosophical Magazine A, v. 52, n. 2, p. 207-224, http://dx.doi.org/10.1080/01418618508237619

Carter, R. E., 1961, Mechanism of solid-state reaction between magnesium oxide and aluminum oxide and between magnesium oxide and ferric oxide: Journal of the American Ceramic Society, v. 44, n. 3, p. 116-120, http://dx.doi.org/10.1111/j.1151-2916.1961.tb13724.x

Castaing, J., Munoz, A., and Rodriguez, A., 2002, Hardening of rhombohedral twinning in sapphire $\left(\alpha-\mathrm{Al}_{2} \mathrm{O}_{3}\right)$ by basal slip dislocations: Philosophical Magazine A, v. 82, n. 7, p. 1419-1431, http:// dx.doi.org/10.1080/01418610208235680

Christian, J. W., 1951, A theory of the transformation in pure cobalt: Proceedings of the Royal Society A Mathematical Physical and Engineering Sciences, v. 206, n. 1084, p. 51-64, http://dx.doi.org/10.1098/ rspa. 1951.0055

Copley, S. M., and Pask, J. A., 1965, Plastic deformation of MgO single crystals up to $1600{ }^{\circ} \mathrm{C}$ : Journal of the American Ceramic Society, v. 48, n. 3, p. 139-146, http://dx.doi.org/10.1111/j.1151-2916.1965. tb16050.x

Donlon, W. T., Heuer, A. H., and Mitchell, T. E., 1998, Compositional softening in Mg-Al spinel: Philosophical Magazine A, v. 78, n. 3, p. 615-641, http://dx.doi.org/10.1080/01418619808241926

Dybkov, V. I., 2009, The growth kinetics of intermetallic layers at the interface of a solid metal and a liquid solder: JOM, v. 61, n. 1, p. 76-79, http://dx.doi.org/10.1007/s11837-009-0015-9

Fiquet, G., Richet, P., and Montagnac, G., 1999, High-temperature thermal expansion of lime, periclase, corundum and spinel: Physics and Chemistry of Minerals, v. 27, n. 2, p. 103-111, http://dx.doi.org/ $10.1007 / \mathrm{s} 002690050246$

Fisler, D. K., Mackwell, S. J., and Petsch, S., 1997, Grain boundary diffusion in enstatite: Physics and Chemistry of Minerals, v. 24, p. 264-273, http://dx.doi.org/10.1007/s002690050038

Gardés, E., Wunder, B., Wirth, R., and Heinrich, W., 2011, Growth of multilayered polycrystalline reaction rims in the $\mathrm{MgO}-\mathrm{SiO}_{2}$ system, part I: experiments: Contributions to Mineralogy and Petrology, v. 161, n. 1, p. 1-12, http://dx.doi.org/10.1007/s00410-010-0517-z

Götze, L. C., Abart, R., Rybacki, E., Keller, L. M., Petrishcheva, E., and Dresen, G., 2010, Reaction rim growth in the system $\mathrm{MgO}-\mathrm{Al}_{2} \mathrm{O}_{3}-\mathrm{SiO}_{2}$ under uniaxial stress: Mineralogy and Petrology, v. 99, n. 3-4, p. 263277, http://dx.doi.org/10.1007/s00710-009-0080-3 
Haasen, P., 1985, Dislocations and properties of real materials: London, The Institute of Metals, $312 \mathrm{p}$.

Hallstedt, B., 1992, Thermodynamic assessment of the system $\mathrm{MgO}-\mathrm{Al}_{2} \mathrm{O}_{3}$ : Journal of the American Ceramic Society, v. 75, n. 6, p. 1497-1507, http://dx.doi.org/10.1111/j.1151-2916.1992.tb04216.x

Hesse, D., Senz, S. T., Scholz, R., Werner, P., and Heydenreich, J., 1995, Structure and morphology of the reaction fronts during the formation of $\mathrm{MgAl}_{2} \mathrm{O}_{4}$ thin films by solid state reaction between $R$-cut sapphire substrates and MgO films: Interface Science, v. 2, n. 3, p. 221-237, http://dx.doi.org/10.1007/ BF00215169

Heuer, A. H., 1966, Deformation twinning in corundum: Philosophical Magazine, v. 13, n. 122, p. 379-393, http:/ /dx.doi.org/10.1080/14786436608212616

Heuer, A. H., and Castaing, J., 1985, Structure and properties of $\mathrm{MgO}$ and $\mathrm{Al}_{2} \mathrm{O}_{3}$ ceramics, in Advances in Ceramics, v. 10: Columbus, Ohio, American Ceramic Society, 238 p.

Heuer, A. H., Lagerlof, K. P. D., and Castaing, J., 1998, Slip and twinning dislocations in sapphire $\left(\alpha-\mathrm{Al}_{2} \mathrm{O}_{3}\right)$ : Philosophical Magazine A, v. 78, n. 3, p. 747-763, http://dx.doi.org/10.1080/01418619808241934

Hielscher, R., Schaeben, H., and Siemes, H., 2010, Orientation distribution within a single hematite crystal: Mathematical Geosciences, v. 42, n. 4, p. 359-375, http://dx.doi.org/10.1007/s11004-010-9271-z

Joachim, B., Gardés, E., Abart, R., and Heinrich, W., 2011, Experimental growth of åkermanite reaction rims between wollastonite and monticellite: evidence for volume diffusion control: Contributions to Mineralogy and Petrology, v. 161, n. 3, p. 389-399, http://dx.doi.org/10.1007/s00410-010-0538-7

Joachim, B., Gardés, E., Velickov, B., Abart, R., and Heinrich, W., 2012, Experimental growth of diopside + merwinite reaction rims: The effect of water on microstructure development: American Mineralogist, v. 97, n. 1, p. 220-230, http://dx.doi.org/10.2138/am.2011.3819

Joesten, R., and Fisher, G., 1988, Kinetics of diffusion-controlled mineral growth in the Christmas Mountains (Texas) contact aureole: Geological Society of America Bulletin, v. 100, n. 5, p. 714-732, http:// dx.doi.org/10.1130/0016-7606(1988) 100<0714:KODCMG >2.3.CO;2

Joesten, R. L., 1991, Kinetics of coarsening and diffusion-controlled mineral growth: Reviews in Mineralogy and Geochemistry, v. 26, n. 1, p. 507-582.

Jung, I. H., Decterov, S. A., and Pelton, A. D., 2004, Critical thermodynamic evaluation and optimization of the $\mathrm{MgO}-\mathrm{Al}_{2} \mathrm{O}_{3}, \mathrm{CaO}-\mathrm{MgO}-\mathrm{Al}_{2} \mathrm{O}_{3}$, and $\mathrm{MgO}-\mathrm{Al}_{2} \mathrm{O}_{3}-\mathrm{SiO}_{2}$ systems: Journal of Phase Equilibria and Diffusion, v. 25, n. 4, p. 329-345, http://dx.doi.org/10.1007/s11669-004-0151-4

Keller, L. M., Götze, L. C., Rybacki, E., Dresen, G., and Abart, R., 2010, Enhancement of solid-state reaction rates by non-hydrostatic stress effects on polycrystalline diffusion kinetics: American Mineralogist, v. 95, n. 10, p. 1399-1407, http://dx.doi.org/10.2138/am.2010.3372

Kirkendall, E. O., 1942, Diffusion of zinc in alpha brass: Transactions of the AIME, v. 147, p. 104-109.

Koch, E., and Wagner, C., 1936, Über die bildung von $\mathrm{Ag}_{2} \mathrm{HgJ} 4$ aus $\mathrm{AgJ}$ und $\mathrm{HgJ} 2$ durch reaktion im festen zustand: Zeitschrift für Physikalische Chemie, v. 34, p. 317-321.

Li, D. X., Pirouz, P., Heuer, A. H., Yadavalli, S., and Flynn, C. P., 1992, A high-resolution electron microscopy study of $\mathrm{MgO} / \mathrm{Al}_{2} \mathrm{O}_{3}$ interfaces and $\mathrm{MgAl}_{2} \mathrm{O}_{4}$ spinel formation: Philosophical Magazine A, v. 65, n. 2 , p. 403-425, http://dx.doi.org/10.1080/01418619208201530

Milke, R., Wiedenbeck, M., and Heinrich, W, 2001, Grain boundary diffusion of $\mathrm{Si}, \mathrm{Mg}$, and $\mathrm{O}$ in enstatite reaction rims: a SIMS study using isotopically doped reactants: Contributions to Mineralogy and Petrology, v. 142, n. 1, p. 15-26, http://dx.doi.org/10.1007/s004100100277

Milke, R., Abart, R., Kunze, K., Koch-Müller, M., Schmid, D., and Ulmer, P., 2009, Matrix rheology effects on reaction rim growth I: evidence from orthopyroxene rim growth experiments: Journal of Metamorphic Geology, v. 27, n. 1, p. 71-82, http://dx.doi.org/10.1111/j.1525-1314.2008.00804.x

Morawiec, A., 1997, Distributions of misorientation angles and misorientation axes for crystallites with different symmetries: Acta Crystallographica Section A Foundations of Crystallography, v. A53, n. 3, p. 273-285, http://dx.doi.org/10.1107/S0108767396015115

Petrishcheva, E., and Renner, J., 2005, Two-dimensional analysis of pore drag and drop: Acta Materialia, v. 53, n. 9, p. 2793-2803, http://dx.doi.org/10.1016/j.actamat.2005.02.040

Pfeiffer, T., and Schmalzried, H., 1989, Spinel formation: A detailed analysis: Zeitschrift für Physikalische Chemie, v. 161, p. 1-17, http://dx.doi.org/10.1524/zpch.1989.161.Part_1_2.001

Rossi, R. C., and Fulrath, R. M., 1963, Epitaxial growth of spinel by reaction in the solid state: Journal of the American Ceramic Society, v. 46, n. 3, p. 145-149, http://dx.doi.org/10.1111/j.1151-2916.1963. tb11699.x

Sack, R., 1982, Spinels as petrogenetic indicators: Activity-composition relations at low pressures: Contributions to Mineralogy and Petrology, v. 79, n. 2, p. 169-186, http://dx.doi.org/10.1007/BF01132886

Sack, R. O., and Ghiorso, M. S., 1991, An internally consistent model for the thermodynamic properties of $\mathrm{Fe}-\mathrm{Mg}$-titanomagnetite-aluminate spinels: Contributions to Mineralogy and Petrology, v. 106, n. 4, p. 474-505, http://dx.doi.org/10.1007/BF00321989

Schmalzried, H., 1962, Reaktionsmechanism der spinellbildung im festen zustand: Zeitschrift für Physikalische Chemie Neue Folge, v. 33, n. 1-4, p. 111-128, http://dx.doi.org/10.1524/zpch.1962.33.1_4.111 1981, Some aspects of cation diffusion in spinel-type oxides: Zeitschrift für Physikalische Chemie Neue Folge, v. 124, n. 1, p. 65-73, http://dx.doi.org/10.1524/zpch.1981.124.1.065

Schmid, F., and Harris, D. C., 1998, Effects of crystal orientation and temperature on the strength of sapphire: Journal of the American Ceramic Society, v. 81, n. 4, p. 885-893, http://dx.doi.org/10.1111/ j.1151-2916.1998.tb02423.x

Scott, W., and Orr, K. K., 1983, Rhombohedral twinning in alumina: Journal of the American Ceramic Society, v. 66, n. 1, p. 27-32, http://dx.doi.org/10.1111/j.1151-2916.1983.tb09962.x

Sieber, H., Hesse, D., Pan, X., Senz, S. T., Heydenreich, J., and Pan, X., 1996, TEM investigations of spinel-forming solid state reactions: Mechanism, film orientation, and interface structure during $\mathrm{MgAl}_{2} \mathrm{O}_{4}$ formation on $\mathrm{MgO}$ (001) and $\mathrm{Al} 2 \mathrm{O} 3$ (1-1.2) single crystal substrates: Zeitschrift fur Anorganische und Allgemeine Chemie, v. 622, n. 10, p. 1658-1666, http://dx.doi.org/10.1002/zaac.19966221007 
Sieber, H., Hesse, D., and Werner, P., 1997a, Misfit accommodation mechanisms at moving reaction fronts during topotaxial spinel-forming thin-film solid-state reactions: A high-resolution transmission electron microscopy study of five spinels of different misfits: Philosophical Magazine A, v. 75, n. 4, p. 889-908, http:/ /dx.doi.org/10.1080/01418619708214000

Sieber, H., Werner, P., and Hesse, D., 1997b, The atomic structure of the reaction front as a function of the kinetic regime of a spinel-forming solid-state reaction: Philosophical Magazine A, v. 75, n. 4, p. 909-924, http://dx.doi.org/10.1080/01418619708214001

Snow, J., and Heuer, A., 1973, Slip systems in $\mathrm{Al}_{2} \mathrm{O}_{3}$ : Journal of the American Ceramic Society, v. 56, n. 3 , p. 153-157, http://dx.doi.org/10.1111/j.1151-2916.1973.tb15432.x

Vernon, R., 2004, A practical guide to rock microstructure: Cambridge, Cambridge University Press, 594 p.

Watson, E. B., and Price, J. D., 2002, Kinetics of the reaction $\mathrm{MgO}+\mathrm{Al}_{2} \mathrm{O}_{3} \rightarrow \mathrm{MgAl}_{2} \mathrm{O}_{4}$ and $\mathrm{Al}-\mathrm{Mg}$ interdiffusion in spinel at 1200 to $2000^{\circ} \mathrm{C}$ and 1.0 to $4.0 \mathrm{GPa}$ : Geochimica et Cosmochimica Acta, v. 66, n. 12, p. 2123-2138, http://dx.doi.org/10.1016/S0016-7037(02)00827-X

Whitney, W. P., II, and Stubican, V. S., 1971, Interdiffusion studies in the system $\mathrm{MgO}-\mathrm{Al}_{2} \mathrm{O}_{3}$ : Journal of Physics and Chemistry of Solids, v. 32, n. 2, p. 305-312, http://dx.doi.org/10.1016/0022-3697(71)90015-1

Yoo, J. S., Bhattacharyya, A. A., and Radlowski, C. A., 1991, De-SOx catalyst: an XRD study of magnesium aluminate spinel and its solid solutions: Industrial and Engineering Chemistry Research, v. 30, n. 7, p. 1444-1448, http://dx.doi.org/10.1021/ie00055a007

Yund, R. A., 1997, Rates of grain boundary diffusion through enstatite and forsterite reaction rims: Contributions to Mineralogy and Petrology, v. 126, n. 3, p. 224-236, http://dx.doi.org/10.1007/ s004100050246 